\title{
Radon Exposure-Therapeutic Effect and Cancer Risk
}

\author{
Andreas Maier $\left.{ }^{1,+}{ }^{(}\right)$, Julia Wiedemann ${ }^{1,+}$, Felicitas Rapp ${ }^{1}\left(\mathbb{D}\right.$, Franziska Papenfuß ${ }^{1}$, Franz Rödel ${ }^{2}$, \\ Stephanie Hehlgans ${ }^{2}{ }^{\oplus}$, Udo S. Gaipl ${ }^{3}{ }^{-}$, Gerhard Kraft ${ }^{1}$, Claudia Fournier ${ }^{1,+}$ and Benjamin Frey ${ }^{3, *,+}+\mathbb{C}$ \\ 1 Biophysics Department, GSI Helmholtzzentrum für Schwerionenforschung GmbH, \\ 64291 Darmstadt, Germany; a.maier@gsi.de (A.M.); j.wiedemann@gsi.de (J.W.); f.rapp@gsi.de (F.R.); \\ f.papenfuss@gsi.de (F.P.); g.kraft@gsi.de (G.K.); c.fournier@gsi.de (C.F.) \\ 2 Department of Radiotherapy and Oncology, University Hospital Frankfurt, Goethe-Universität Frankfurt am \\ Main, 60590 Frankfurt am Main, Germany; franz.roedel@kgu.de (F.R.); stephanie.hehlgans@kgu.de (S.H.) \\ 3 Translational Radiation Biology, Department of Radiation Oncology, Universitätsklinikum Erlangen, \\ Friedrich-Alexander-Universität Erlangen-Nürnberg, 91054 Erlangen, Germany; udo.gaipl@uk-erlangen.de \\ * Correspondence: benjamin.frey@uk-erlangen.de \\ + These authors contributed equally.
}

check for

updates

Citation: Maier, A.; Wiedemann, J.; Rapp, F.; Papenfuß, F.; Rödel, F.; Hehlgans, S.; Gaipl, U.S.; Kraft, G.; Fournier, C.; Frey, B. Radon Exposure-Therapeutic Effect and Cancer Risk. Int. J. Mol. Sci. 2021, 22, 316. https://doi.org/10.3390/ijms 22010316

Received: 18 November 2020 Accepted: 24 December 2020 Published: 30 December 2020

Publisher's Note: MDPI stays neutral with regard to jurisdictional clai$\mathrm{ms}$ in published maps and institutional affiliations.

Copyright: $\odot 2020$ by the authors. Licensee MDPI, Basel, Switzerland. This article is an open access article distributed under the terms and conditions of the Creative Commons Attribution (CC BY) license (https:// creativecommons.org/licenses/by/ $4.0 /)$.

\begin{abstract}
Largely unnoticed, all life on earth is constantly exposed to low levels of ionizing radiation. Radon, an imperceptible natural occurring radioactive noble gas, contributes as the largest single fraction to radiation exposure from natural sources. For that reason, radon represents a major issue for radiation protection. Nevertheless, radon is also applied for the therapy of inflammatory and degenerative diseases in galleries and spas to many thousand patients a year. In either case, chronic environmental exposure or therapy, the effect of radon on the organism exposed is still under investigation at all levels of interaction. This includes the physical stage of diffusion and energy deposition by radioactive decay of radon and its progeny and the biological stage of initiating and propagating a physiologic response or inducing cancer after chronic exposure. The purpose of this manuscript is to comprehensively review the current knowledge of radon and its progeny on physical background, associated cancer risk and potential therapeutic effects.
\end{abstract}

Keywords: radon therapy; low doses; $\alpha$-particles; clinical studies; anti-inflammatory effects; changes immune activation; osteoimmunological changes

\section{Introduction}

Radon is a naturally occurring, radioactive noble gas that contributes as the largest single fraction to radiation exposure from natural sources [1]. It is produced by various decay chains of uranium and thorium and has no stable isotopes [2]. However, there are three naturally occurring isotopes: ${ }^{222} \mathrm{Rn}$ with a half-life of 3.825 days, originating from the uranium series, ${ }^{220} \mathrm{Rn}$ (thoron, $\mathrm{T} 1 / 2=55.6 \mathrm{~s}$ ) derived from the thorium series and ${ }^{219} \mathrm{Rn}$ (actinon, T1/2 = 3.96 s) from the actinium series [3]. As these isotopes are noble gases, there are no known chemical interactions at physiological temperatures [4].

In 1899, Rutherford and Owens discovered radiation emanating from thorium oxide and uranium [5]. In further studies, Rutherford identified a radioactive substance, permanently emitted from thorium compounds, which turned out to be ${ }^{220} \mathrm{Rn}$ [6]. In parallel, Marie and Pierre Curie discovered the ${ }^{222} \mathrm{Rn}$ isotope by studying the emanation from radium, which stayed radioactive for several days due to the comparatively long half-life of this isotope [7]. Based on the work of Rutherford and Curie, Dorn confirmed their results with both uranium and thorium [8], while Debierne discovered the isotope ${ }^{219} \mathrm{Rn}$ by measuring radioactive emanation from actinium [9].

Due to their half-lives of 3.8 days and $55.6 \mathrm{~s}$, respectively, ${ }^{222} \mathrm{Rn}$ and ${ }^{220} \mathrm{Rn}$ isotopes are the only radon-nuclides that exist long enough to emanate from natural rocks and soil where they are formed. Due to its short half-life, ${ }^{220} \mathrm{Rn}$ has a shorter diffusion length than ${ }^{222} \mathrm{Rn}$. Nevertheless, if ${ }^{220} \mathrm{Rn}$ is present, it can contribute significantly to the total inhalation 
dose and should not be neglected [10]. Thus, both isotopes, ${ }^{222} \mathrm{Rn}$ and ${ }^{220} \mathrm{Rn}$, are the only significant contributors to human radon exposure from natural sources [1]. After emanation in ambient air, radon isotopes accumulate indoors and represent the most important contributor to annual radiation dose of the population [11,12]. However, the radon activity concentrations in homes highly depend on geological conditions such as the uranium versus thorium content and the gas permeability of the soil. In addition, anthropogenic factors such as building materials, ventilation systems, or living habits play a significant role. Interestingly, some building materials are not only sources for indoor ${ }^{222} \mathrm{Rn}$ but also ${ }^{220} \mathrm{Rn}$ exposure [1], and its concentration varies considerably with the distance from the wall and the airflow [13]. All these facts together lead to large regional differences $[12,14,15]$ and, in average, to higher radon concentration indoors than outdoors [16]. Regions like Kerala in India and cities like Yangjiang (China) or Ramsar (Iran) have particularly high radon concentrations in soil and indoors [17]. However, not only indoor accumulation, but also showering with radon-containing water releases radon to moist air, which represents a substantial source of radon exposure [18]. This fact is supported by measurements of the radon activity concentration in spa treatment rooms during filling of the bathing tubes, enhancing radon activity concentrations [19]. Nevertheless, the level of radon daughter nuclides usually remains low during filling, since they attach to vapor and are removed by ventilation and air circulation [20]. Intake of radon via drinking radon-containing water represents a minor source of exposure compared to inhalation [21].

Both radon isotopes disintegrate into several unstable daughter nuclides, emitting different radiation types (see Table 1 ).

Table 1. Decay scheme of ${ }^{222} \mathrm{Rn}$ and ${ }^{220} \mathrm{Rn}$ [22].

\begin{tabular}{cccccc}
\hline & ${ }^{222} \mathbf{R n}$ & & & & \\
\hline Nuclide & Half-Life & Decay-Mode & Nuclide & Half-Life & Decay-Mode \\
\hline${ }^{222} \mathrm{Rn}$ & $3.825 \mathrm{~d}$ & $\alpha$ & ${ }^{220} \mathrm{Rn}$ & $55 \mathrm{~s}$ & $\alpha, \gamma$ \\
${ }^{218} \mathrm{Po}$ & $3.05 \mathrm{~min}$ & $\alpha$ & ${ }^{216} \mathrm{Po}$ & $0.15 \mathrm{~s}$ & $\alpha$ \\
${ }^{214} \mathrm{~Pb}$ & $26.8 \mathrm{~min}$ & $\beta, \gamma$ & ${ }^{212} \mathrm{~Pb}$ & $10.64 \mathrm{~h}$ & $\beta, \gamma$ \\
${ }^{214} \mathrm{Bi}$ & $19.9 \mathrm{~min}$ & $\beta, \gamma$ & ${ }^{212} \mathrm{Bi}$ & $60.6 \mathrm{~min}$ & $\alpha, \beta, \gamma$ \\
${ }^{214} \mathrm{Po}$ & $164 \mu \mathrm{s}$ & $\alpha$ & ${ }^{212} \mathrm{Po}$ & $304 \mathrm{~ns}$ & $\alpha$ \\
${ }^{210} \mathrm{~Pb}$ & $22.3 \mathrm{a}$ & $\beta, \gamma$ & ${ }^{208} \mathrm{Tl}$ & $3.05 \mathrm{~min}$ & $\beta, \gamma$ \\
${ }^{210} \mathrm{Bi}$ & $5.0 \mathrm{~d}$ & $\beta, \gamma$ & ${ }^{208} \mathrm{~Pb}$ & stable & \\
${ }^{210} \mathrm{Po}$ & $138.4 \mathrm{~d}$ & $\alpha$ & & & \\
${ }^{206} \mathrm{~Pb}$ & stable & & & & \\
\hline
\end{tabular}

After decay in air, the nuclides react in less than one second with trace gases and air vapor, forming clusters of $0.5-5 \mathrm{~nm}$ size, also called the "unattached progeny", which are positively charged and highly mobile [23,24]. Within $100 \mathrm{~s}$, those clusters may attach to aerosol particles by diffusion, described by gas kinetic laws. The parameter that mostly influences the fraction of attached daughter nuclides is the number of aerosols [25] with the influence of electrostatic forces considered to be negligible $[23,26]$. The formed particles build the "attached progeny" for which diffusion coefficient measurements showed three distinct size ranges. These are called nucleation mode covering sizes from 10-100 nm, accumulation mode with particle sizes ranging from 100-450 nm and the coarse mode for particles larger than $1 \mu \mathrm{m}$ [1]. The size distribution is strongly influenced by the aerosol mixture in the air. Accordingly, all studies show slightly different results but were consistent in the fact that the highest activity originates from radon decay products bound to aerosols associated with the accumulation mode $[1,25,27]$. Moreover, measurements showed that over $90 \%$ of the activity is associated with the "attached progeny" while the "unattached progeny" accounts for only 10\% [21,23], being, in turn, three to five times more effective in dose commitment due to its smaller size [28].

Once built, solid daughter nuclei deposit on surfaces such as walls and furniture by different mechanisms (sedimentation, impaction, interception and diffusion), resulting 
in a lower activity concentration of the decay products in indoor-air than expected from equilibrium with radon $[23,27]$. This and other removal processes reduce the concentration of radon decay products, depending on a number of interlinked parameters such as the loss by radioactive decay, ventilation or the aforementioned deposition on room surfaces [29].

\section{Intake and Distribution of Radon in the Human Organism}

There are different routes of intake for radon and its solid progeny into the human body: during inhalation through the epithelial surfaces of lung, uptake through the skin while bathing in radon-containing water and by ingestion via the gastrointestinal tract by drinking radon-containing water. The incorporation of radon via drinking water is not further addressed here, as this route only plays a minor role for therapeutic application as well as public health [21].

\subsection{Inhalation}

The primary route of incorporation is inhalation, which occurs in radon galleries and in radon-contaminated buildings, leading to diffusion of radon gas through the lung epithelium and deposition of the solid progeny in the lung. The $\alpha$-particles originating in this decay chain are the major contributors to the physical absorbed dose, whereas $\beta$ - and $\gamma$-decay contributes to around $10 \%$ of the deposited energy [28,30]. For radiation protection purposes, a proper risk assessment is necessary and the exposure to certain radon activity concentrations has to be converted into an effective dose. For this, the absorbed energy has to be determined leading to the physical dose which is multiplied with radiation and organ specific weighting factors, considering the ionization pattern of various radiation types and the relative sensitivity of different tissues.

Considering the inhaled progeny, the lung equivalent-dose contributes to more than $95 \%$ of the total effective dose [31] because the progeny will largely deposit on the surface of the respiratory tract and decay before clearance can occur [1,28]. Additionally, simulations with various models of chronic exposure suggest that decay products cover more than $95 \%$ of the total effective dose received by exposure to radon while the radon gas itself contributes to less than $5 \%[1,28,31-33]$. The reason is that, presumably, only about $1 \%$ of the inhaled gas is absorbed by the blood $[33,34]$. Assuming the inhalation of pure radon gas without progeny, simulations revealed that $30-50 \%$ of the effective dose is deposited in the lung due to radon decay in the airways.

Model calculations based on animal experiments describe the deposition of particles, which is different for attached and unattached radon progeny. The aerosols to which the progeny are attached show different characteristics (size, shape, and others). If combined with detailed morphometry and physiological parameters of the lung (breathing pattern and lung geometry) three different deposition mechanisms are to be discriminated: inertial impaction, sedimentation, and diffusion (see Figure 1). Despite these measurements not being performed with radon decay products, the basic mechanisms are supposed to be the same. Although there are a lot of simulations, the exact dose to different parts of the lung remains unclear as there are no experimental data to ascertain these simulations.

In the upper region of the respiratory tract (nasopharynx, trachea, and upper bronchi), particles with 2-20 $\mu \mathrm{m}$ diameter keep their trajectory, despite changes in direction of air stream because of their inertial momentum and get stuck there. This process is called inertial impaction. Sedimentation describes the settling of smaller particles $(0.1-50 \mu \mathrm{m})$ due to gravity in the upper respiratory tract and mainly in bronchioles and alveoli. Diffusion due to Brownian motion increases with decreasing particle size $(<0.2 \mu \mathrm{m})$ and predominates in the gas exchange regions of the lung, whereby the "unattached progeny" $(0.5-5 \mathrm{~nm})$ mainly deposits directly after entering the respiratory tract (see Figure 1). The total lung deposition shows a minimum for particle sizes ranging from $0.2-0.5 \mu \mathrm{m}$ [35-37] as these particles are too lightweight for sedimentation but have a decreased diffusion coefficient due to their size. Moreover, turbulences and inverse flows cause an inhomogeneous 
deposition pattern and hot spots of deposition at bifurcations from larger into smaller airways [37].

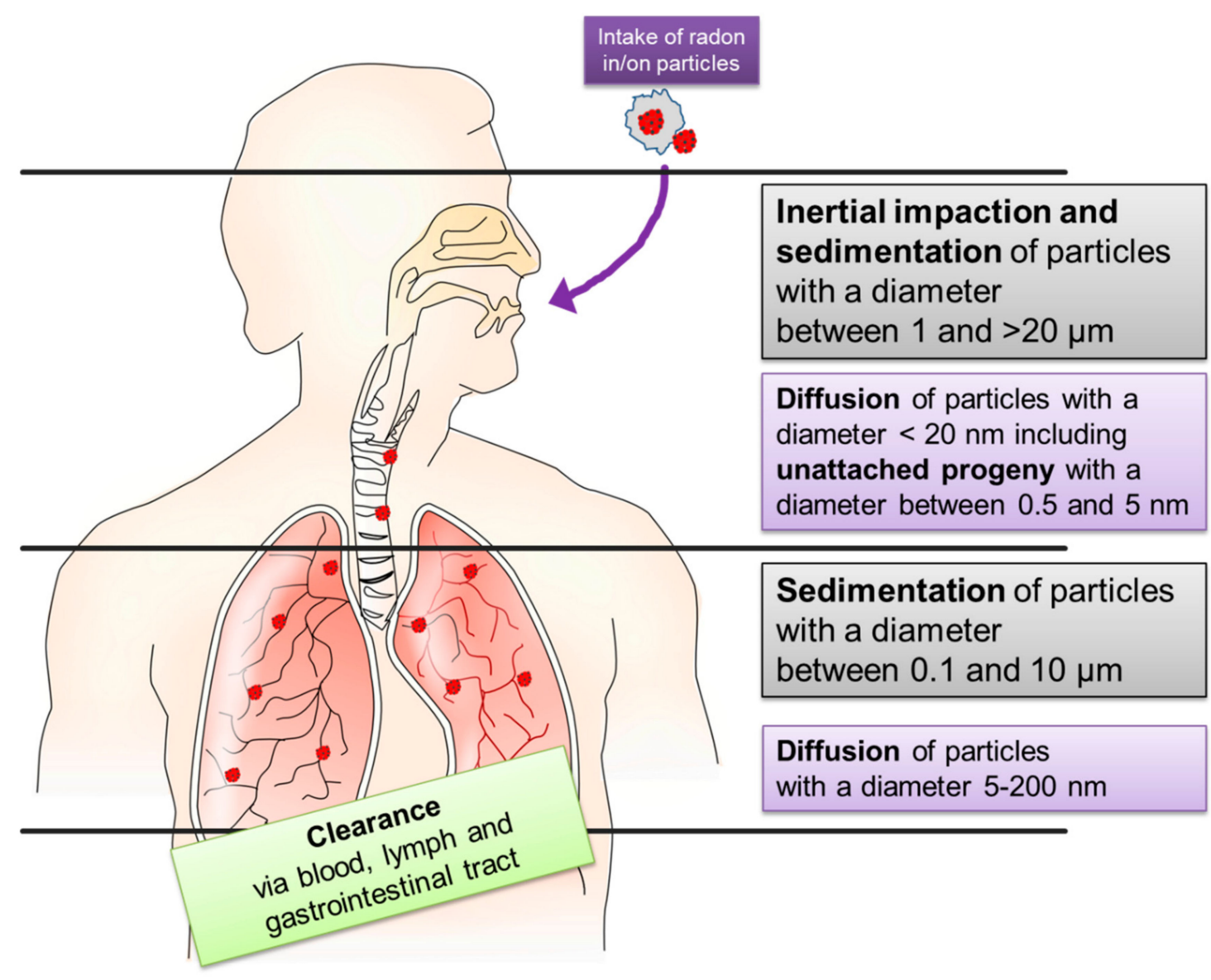

Figure 1. Different deposition mechanism for attached and unattached particles with various particle sizes. Drawing was taken from OpenClipart-Vectors on Pixabay under Creative CommonsCC0.

In the lung models used by the International Commission for Radiation Protection (ICRP), are considered to have different sensitivities to radiation at different regions of the respiratory tract [1], and basal and mucous cells in the bronchial epithelium are regarded as particularly radiosensitive [38]. Further, simulation studies suggest that the highest dose from radon decay products is deposited at the bifurcation of the trachea [39], with the latter not to be the most sensitive region.

Besides deposition, the reversed process of removal has to be considered for dose estimation. After deposition, solid daughter nuclei can be eliminated by clearance mechanisms. General knowledge of the physiological mechanisms suggest three primary routes of clearance: via the bloodstream, the lymphatic drainage system, or the gastrointestinal tract [35], depending on the characteristics of the particles used and the settings of the respective experiments (e.g., particle number, location in the respiratory tract) [40-42]. In the trachea or bronchial tubes, clearance mostly occurs by mucociliary transport or phagocytosis by pulmonary alveolar macrophages. Below the ciliated airways in the area of gas exchange, clearance, and transport to other tissues takes place via the bloodstream, lymphatic channels, or phagocytosis. Depending on the main mechanism of clearance different regions of the respiratory tract show different predominant clearance rates, whereby a superimposition of different clearing rates can occur in one lung region $[35,40,43]$. 


\subsection{Incorporation via Skin}

In homes and especially in radon galleries, inhalation of radon via the lung plays a dominant role in radon uptake. In spa treatments with radon-containing water and in vapor cabinets, radon and its progeny enter the body via the skin epithelium, while inhalation only plays a minor role as the head of the patients usually remains outside the treatment tub in the well-ventilated treatment rooms [44]. In open bath tubes radon- and progenycontaining vapor is also inhaled through the lung [45].

As for the lung epithelium, radon can diffuse through the skin. When reaching the bloodstream, it is distributed throughout the body. A part is transported back to the lung and exhaled [46]. After entering radon-containing water, the radon activity concentration in the exhalation air of patients undergoing spa therapy increases very fast, reaching saturation levels after approximately $20 \mathrm{~min}$ [46]. Afterwards, it is reported that radon is removed via breathing in an exponential fashion within a few minutes [44], whereas the decay products are mainly eliminated via excretion [47]. This means that the uptake and elimination of radon in and out of the human body is a fast process, while the decay products can stay in the body for a considerably longer time.

For radon bathing, it was stated that a minor fraction of the radon progeny will be adsorbed by the skin, but the major part will be desorbed after their decay. In radon galleries and vapor bathes, this is not the case, and radon progenies will stay on the skin. In both cases, radon progeny deposit a considerable energy to the skin, which is higher after treatment in a radon gallery than after radon bath [48,49]. According to experimental results reported by Tempfer and colleagues, the radon progeny activity shows an exponential decrease with skin depth to $20-30 \%$ of the surface activity at a depth of $20 \mu \mathrm{m}$ [48]. This is attributed to diffusion and transport of progeny along hair capillaries and micro-crevices [48].

\subsection{Distribution}

Measurements of the distribution of primary radon in the human body after exposure are scarce. Inhalation experiments with the radioactive noble gas krypton show that the uptake and elimination of krypton $\left({ }^{79} \mathrm{Kr},{ }^{81} \mathrm{Kr}\right)$ activity at knee and arms was influenced by the rate of blood flow, as better circulation leads to faster kinetics with half times between 6-320 $\mathrm{min}$ [50]. One of the few measurements of radon activity concentrations in humans was obtained by exposure of a test person to high levels of radon and subsequent analyses of the radon concentration in the exhaled air. Five distinct elimination coefficients were determined, which were correlated with different body sites to conclude on the retention and exhalation of radon gas due to its solubility in body tissues [51]. There are few additional data mainly used for modelling purposes on the retention of radioxenon in the human body [52], in dogs [53], and for krypton in guinea pigs [54].

Most of the data for radon solubility are derived from animal experiments obtained in rats, where the highest value was determined for adipose tissue (omental fat), with a more than 10 times increased solubility as compared to other tissues like brain, liver, or muscle $[34,38,55]$, although the maximum radon concentration is attained much slower. Adipose tissue shows a two-component built-up with different time constants of 21 and $138 \mathrm{~min}$ [56]. Calculations further indicate an elevated dose to red bone marrow due to the high fat cell content [57]. More recently, comparable results for the solubility of radon in different organs were obtained in mice [55]. In vitro measurements of radon solubility coefficients in fatty acids indicate an interrelationship between the number of carbon atoms in the fatty acid and the solubility per molecule [58]. In addition, radon is not equally distributed between different compounds. Although radon solubility is highly dependent on external conditions like temperature or salinity when measuring in water [59], measurements and molecular dynamic simulations revealed that radon is more soluble in fatty acids than in water because of the stronger cross bonding of the water molecules compared to fat [60]. 
In contrast to the pure solubility, which is a passive process, radon, in addition, is transported actively via the bloodstream and its further exchange via diffusion is governed by radon solubility. The resulting inhomogeneous distribution between different tissues determines the dose to different organs. For subsequent dose calculations, measurements of activity concentrations, and determination of diffusion and solubility of radon in different tissues is required $[28,61]$.

For such multiparametric calculations, model systems are used, which usually consist of different compartments with specific morphometric and physiological parameters, conterminously with different tissue and organs in the human body $[31,62,63]$. Even though a model for the calculation of absorbed dose rates to organs and tissues in mice, rats, and humans, provide similar values for the different species [34], the input parameters for radon distribution in these models usually are derived from animal data, making it difficult to transmit these values to humans.

Besides the dependence on the model and the physiological parameters, the calculated doses are highly dependent on factors like exposure duration, radon activity concentration, amount of radon decay products in air, and size of the formed particles [64]. Therefore, we consider it difficult to provide exact dose values, but some statements on the relative dose depositions seem to be supported by the data. The highest dose is deposited in the lung, mainly caused by radon decay products during inhalation of primary radon [28]. This is supported by biodosimetric measurements in mice after radon exposure, which show a three times higher dose in the lung compared to kidney, heart, or liver [65].

As the reported measurements and simulations are consistent regarding high solubility of radon in adipose tissue, it seems reasonable to assume that this is also the reason for the calculated higher doses in bone marrow and female breast, which is approximately half of the dose to the lung [31,62]. However, the inner organs outside the respiratory tract receiving the highest dose from radon decay products are the kidneys [28].

In conclusion, the question remains whether this inhomogeneous distribution and the hot spots in fatty tissue are important to clarify the mechanistic basis in the clinical effects observed in patients and must be related to the exposure, i.e., the integrated radon activity concentrations. Nevertheless, radon solubility coefficients are weak points in these models, as these values strongly depend on the scarce parameters as mentioned before $[31,34,63]$.

\section{Cancer Risk}

Risk estimation is important for chronic exposure to radon at working places as well as in homes, but it is indispensable for a balanced risk to benefit evaluation for therapeutic applications. The epidemiological studies that are available center on chronic (i.e., years of daily, continuous) exposure, either occupational or environmental. In contrast, non-chronic radon therapy typically covers up to 10 treatment sessions (i.e., treatment time of 20 to 60 min daily) in one series and normally performed once a year. Unfortunately, there are no epidemiologic data about a therapeutic exposure to radon reported up to now.

The short-living, $\alpha$-emitting decay products together with the primary radon contribute significantly to the exposure of humans from natural sources [66]. For a long time, there has been strong evidence that these isotopes are the causative agent for lung cancer induction in miners when deposited in the respiratory tract. So, an increased risk for the development of lung cancer was shown for occupational exposure of minors in mountain galleries to radon and its progeny [16,67]. There is consent that environmental exposure to radon is the second leading cause of lung cancer induction after cigarette smoking $[14,17]$. The excess risk for lung cancer induction due to radon exposure and due to smoking act synergistically in a sub-multiplicative interaction, while an additive relation was rejected by modeling the epidemiologic data sets $[68,69]$.

For risk estimation, the evaluated occurrence of lung cancer must be related to the exposure, i.e., the integrated radon activity concentrations. One problem for epidemiological studies is that the radon activity concentrations during exposure to radon and its progeny depend on environmental and behavioral factors, leading to highly variable 
concentrations. The exact determination would be important for risk assessment but is difficult to achieve, in particular retrospectively [67]. However, epidemiological studies for chronic exposure show a significant increase for risk of lung cancer with increasing radon concentrations [70,71] and exposure duration [72]. In the study of Darby et al., an increase in the risk of lung cancer of $16 \%$ per $100 \mathrm{~Bq} / \mathrm{m} 3$ (95\% confidence interval $5-31 \%$ ) was found in a collaborative meta-analysis of 13 case-controlled studies [73]. These findings and comply with cohort studies of miners with low exposure rates over long times [74]. Age at and time since exposure modifies the excess relative risk per cumulative exposure. The risk decreases significantly by increasing the time at and since exposure [68]. Overall, lung cancer mortality and radon exposure are correlated linearly [74] without threshold [73]. When adjusting the absolute lifetime risk of lung cancer for smoking status, the risk for never smokers is much lower than that for smokers [72]. The conclusion of these epidemiologic studies is that radon represents a significant public health problem [75], when chronic exposure takes place.

During radon therapy (indications are listed in Table 2), the doses received by the patients in the course of one treatment series (typically consisting of ten sessions of one hour each) are in the same order of magnitude as for the natural annual background radiation due to radon. The major difference is the much shorter time period in which the patients obtain this dose and consequently, the higher dose rate. Therefore, the risk of a radiation/radon-induced severe effects of a radon treatment as prescribed by physicists is only fragmentarily described. The best description of side effects is from Franke A and Franke T analyzing the data of the so called IMuRa trial [76]. They described no acute side effects, which exceed a minor degree and they do not report any radiation-induced severe side effects, even at long term observations. These reports correspond with any other description of trials dealing with radon treatment, as summarized in Table 3. Today, there are two major concerns when extrapolating the carcinogenic effects on patients treated with radon bathes or gallery visits. On the one hand, the dose and duration as well as the frequency of radon contact (including inhalation and skin contact) is completely different. On the other hand, the patients are consuming or have consumed pain relieving drugs for years. The exclusion of the side effects from the radon-induced ones at short or even long follow up time is nearly impossible. Therefore, it is difficult to specify an additional risk due to radon therapy, as there are again additionally many unknown factors like natural background in patient homes due to radon or smoking behavior. Additionally, the impact of dose rate lowers the transferability of risk estimates related to the different exposure scenarios [77]. Precisely for this reason, a reliable value for the excess risk of radon therapy by radon itself cannot be calculated from retrospective or epidemiologic data. So, a potential risk from radon faces the described effect of pain relief even for long term and is therefore ethically negligible.

Besides induction of lung cancer, other organs could be affected. For instance, there are studies on the effects by plate out of radon progeny on the skin to investigate ulceration and dermal atrophy as potential effects. These non-cancer effects were considered as unlikely to occur for irradiation by those nuclides, as they require an irradiation of the dermis. During exposure, deeper layers that cannot be reached by these $\alpha$-particles would need to be irradiated, and this makes a correlation between radon progeny exposure and skin cancer induction unlikely [78]. However, an excess risk of basal cell carcinoma was found for residents of geothermal areas in Iceland chronically exposed to elevated levels of radon, but confounding factors could also not be excluded [79]. The results of a Danish radon study with 51,445 subjects and a mean follow-up of 13.6 years suggests a potential effect on the development of basal cell carcinoma, but again confounding factors like sunlight could not be excluded [80], making the statements on skin effects of radon less reliable.

There is some evidence for a correlation between chronic exposure to radon and mortality due to malignant brain tumors. Nevertheless, this study had a non-robust epidemiological design to confirm this finding [81]. Additionally, in studies on the occurrence of the radon decay products ${ }^{210} \mathrm{Po}$ and ${ }^{210} \mathrm{Bi}$ in the brain of persons suffering from 


\begin{abstract}
Alzheimer's or Parkinson's disease, an inhomogeneous distribution of these nuclides was found, but these findings are not sufficient to draw conclusions concerning correlative underlying mechanisms $[82,83]$.

Suggestions were made on a correlation between myeloid leukemia and chronic radon exposure [57], and a significant positive association between indoor radon and acute myeloid leukemia incidence in children was observed [84]. In sum, based on these epidemiologic data, ${ }^{222} \mathrm{Rn}$ and its decay products are classified as carcinogenic to humans for lung cancer by the International Agency for Research on Cancer (IARC), while data are inconclusive for other cancer entities [85]. In addition, a latency time between irradiation and development of malignancies of 5-7 years for leukemia and 10-60 years for solid tumors was observed [86]. Additionally, the age at exposure and the time since exposure seem to play a role for the risk due to irradiation. This makes it difficult to estimate the cancer risk after therapeutic application of radon.
\end{abstract}

\title{
4. Radon as a Therapeutic Agent
}

In spite of the aforementioned risk associated with radon exposure, it is used as a therapeutic agent. In ancient history, applications of "hot bathes" as well as inhalation were basic medical principles applied for treatment of inflammatory diseases. At the beginning of the 20th century radon was found to be a therapeutic agent in several thermal springs $[87,88]$. Therefore, the rise of so-called radon spas started and the application of radon for relief of pain caused by chronic degenerative diseases became popular. Although there was only clinical experience, the results of several recent trials suggest a positive effect of radon treatment related to pain reduction [87-90].

At present, the main application of radon for therapy is inhalation at former mines or bathing in radon-containing water (Appendix A). As the application procedures and indications for treatments expanded, the EURADON (European Association Radon Spas e.V.) was founded and started to define the indications for radon application, i.e., musculoskeletal and chronic pain diseases as well as pulmonary and gynaecological diseases (see Table 2).

Table 2. List of recommended indications for radon treatment [91].

Musculoskeletal disorders and chronic pain diseases

Cutaneous disorders and diseases
Ankylosing spondylitis and other spondylarthropathies (AS)

Chronic polyarthritis (rheumatoid arthritis, RA)

Chronic arthritis urica

Psoriasis arthropathy

Polymyalgia rheumatic

Arthrosis and osteoarthritis (OA)

Degenerative diseases of the spinal column

Auxiliary treatment consecutive to intervertebral disc operations Osteoporosis

Non-inflammatory soft tissue rheumatism (e.g., fibromyalgia)

Chronic consequences of casualty or sporting injuries

Auxiliary treatment consecutive to orthopedic operations Neuralgia, neuritis, polyneuropathy Multiple Sclerosis (MS)

Insufficiently healing wounds (e.g., ulcus cruris)

Atopic dermatitis (neurodermatitis)

Psoriasis

Scleroderma

Low grade circulatory problems of the skin

Asthma bronchiale

Chronic-obstructive pulmonary diseases (COPD)

Rhinitis allergica

Chronic sinusitis
Pulmonary diseases
Praeclimacteric and climacteric disorders Pelvipethia spastica 


\subsection{Clinical Trials}

In Europe and the United States, radon therapy is under ongoing discussion [92] because many historical trials were not in accordance with today's evidence-based medicine [93]. Especially before 1993, studies did not include control groups or were not randomized. Between 1993 and 2000, only three prospective studies including radon therapy for patients with rheumatic disease were reported [94-96], all of them in German, and one is published as a PhD thesis. Lind-Albrecht investigated the effect of radon treatment in gallery (speleotherapy) versus sauna therapy in ankylosing spondylitis (AS) patients ( $n=100$, nonblinded) and found significant differences in pain reduction between the groups three months after the end of therapy [94]. Pratzel and co-workers [95] investigated pain parameters in a group of patients $(n=46)$ suffering from disorders of the cervical spine up to three months after the end of treatment. In this blinded and randomized study, patients were treated by bathing in radon-containing water (or tap water) (balneotherapy) and a long-lasting pain reduction (up to 3 months) was found only in the radon group. Later on, using the same conditions, the authors reported similar effects for patients with degenerative spinal disorders and osteoarthritis (OA) $(n=52)$ [96].

Due to the scarce database, clinical trials are seriously needed that are conducted according to the rules of global evidence-based medicine [97]. Unfortunately, the number of prospective, randomized, and blinded clinical trials performed, starting from 2000 with a reasonable group size is limited (Table 3). One major problem is the blinding of radon treatment as it is not possible to have a radon-free "sham gallery" for speleotherapy to efficiently separate a radon effect from a placebo effect. Accordingly, radon bathes are more eligible, because they can be applied in a blinded manner.

Therefore, three trials by Franke and colleagues, performed between 2000 and 2013, examined in a prospective and blinded manner the effect of radon/carbon dioxide $\left(\mathrm{CO}_{2}\right)$ bathes on patients suffering from rheumatoid arthritis (RA) [98]. Sixty patients medicated with anti-rheumatic drugs were offered 15 bathes within four weeks with radon/CO2 water (radon activity of $1.3 \mathrm{kBq} / \mathrm{L}$ ) or only $\mathrm{CO}_{2}$-containing water as a control. In addition, the patients had different manual therapies during the bath period and follow-up. Interestingly, both treatment groups had similar early effects, but the effect of pain relief lasted significantly longer in the radon group (up to six months), and confirmatory analyses showed a significant superiority in patients receiving radon balneotherapy [98]. In a subsequent randomized trial published in 2007, 134 patients were enrolled to radon $/ \mathrm{CO}_{2}$ or $\mathrm{CO}_{2}$ balneotherapy only, similar to the first trial [99]. These patients showed no significant difference in pain intensity by visual analogue scale (VAS) between the treatment regimes, but differences increased with increasing follow-up time (up to nine months). In line with that, the confirmatory analysis showed a clear and significant effect of radon balneotherapy: the pain relief lasted longer in the radon group. In addition, drug intake was diminished in this group, resulting in a higher quality of life. However, these trials lacked an effective blinding of the water and were biased, since patients were at a regimen at the health resort during radon application. Further, these patients were allowed to have various manual therapies, whereas the control group had to stay at home [99].

The third trial of Franke et al. [76] addressed the above-mentioned bias problems partially. It was the first multicentric trial with 652 patients treated at different spas in Germany and Austria. This study called IMuRa was prospective, randomized and blinded. Patients suffering from OA, RA, AS and back pain (BP), received 12 bathes either with radon-containing water or the site-specific placebo (i.e., tap water, thermal water, or $\mathrm{CO}_{2}$ thermal water). The superiority of radon in inducing pain-relieving effects was confirmed and the intake of non-steroidal anti-rheumatic drugs (NSARDs) was significantly reduced in radon-treated patients for up to six months. The patients suffering from BP and inflammatory rheumatism (combination of RA and AS in this study) did not benefit from the radon baths as much as patients with OA did in terms of functional capacity.

Based on these findings, the GREWIS alpha consortium (funded by the German ministry of Research,02NUK050) started to analyze the contribution of the immune system in 
radon therapy responsiveness. By this, the RAD-ON01 trial was set up to analyze immunological alterations induced by radon balneotherapy in an explorative manner. One hundred patients enrolled in this study received either nine full radon bathes $(1.2 \mathrm{kBq} / \mathrm{L})$ or radon $/ \mathrm{CO}_{2}$ bathes $(0.6 \mathrm{kBq} / \mathrm{L})$, respectively, in a covered bathtub to minimize radon inhalation. The bathing was double-blinded and whole blood of the patients was analyzed before, during, and at several time points after radon spa by detailed immunophenotyping, getting first hints for immunological markers of pain, bone destruction and inflammation [100-102], as described in more detail below. Similar to the trials described before, a significant pain reduction was quantified by VAS and pain dolorimetry for up to 18 weeks, performed at eight different tender points [103,104].

Several prospective, non-blinded trials conducted with patients at radon galleries were published. Van Tubergen and colleagues recruited 120 AS patients for three weeks of daily treatment in the radon gallery (speleotherapy with hyperthermia, HT) or "normal" steam sauna [105]. These patients also performed physical exercises. Since the patients of the two groups were not supposed to meet, the treatments were conducted at two different spa resorts in Europe. The patients who visited the radon gallery reported a significant and long-lasting ease of their pain. But these positive results could only be detected in a secondary analysis, since the power of the primary study goal (e.g., Bath Ankylosing Spondylitis Functional Index (BASFI), well-being, VAS-score) was too low to show statistical significance. Only a 'pooled index of change' analysis resulted in a significant beneficial effect for AS patients, which lasted up to 40 weeks after the spa-exercise program [105].

Another longitudinal observation of 33 AS patients revealed a significant reduction in the main AS scores, but the study was defined as a pilot trial lacking a control group [106]. Notable effects are described by a significant reduction of pain and enhanced functional behaviour in AS patients [107]. Interestingly, Dischereit et al. reported similar results in a trial with 48 patients (half/half of RA/AS, no blinding or control group) [108]. Here, patients with RA had more benefit from radon application, since the pain-relieving capacity lasted up to three months, while the effects in AS patients were diminished after three weeks [108]. A meta-analysis of several trials pointed out that the observed effects seem to be significantly triggered by bone restoration following radon exposure [109].

In summary, several trials starting from the year 2000 suggested that radon therapy has beneficial effects on patients with painful, degenerative, and inflammatory diseases describing a significant reduction of pain and enhanced mobility as well as increased quality of life. Other indications, singularly analyzed and based on small patient collectives or historic cohorts do not seem to be adequately proven, like dermal inflammatory diseases [110], fibromyalgia [111], and respiratory diseases [112]. 
Table 3. Clinical trials with radon application from year 2000 on.

\begin{tabular}{|c|c|c|c|c|c|c|c|}
\hline $\begin{array}{c}\text { First Author } \\
\text { Year of Publication }\end{array}$ & Trial Design & $\begin{array}{l}\text { Patient Number } \\
\text { Indication }\end{array}$ & Dose & $\begin{array}{l}\text { Type of Exposure } \\
\text { Frequency } \\
\text { Duration }\end{array}$ & $\begin{array}{l}\text { Endpoints and } \\
\text { Timepoints }\end{array}$ & Most Important Findings & Ref. \\
\hline Franke et al., 2000 & $\begin{array}{l}\text { Prospective; } \\
\text { blinded; } \\
\text { randomized }\end{array}$ & 60 patients RA & $\begin{array}{l}\text { Radon group: } \\
1.3 \mathrm{kBq} / \mathrm{L}, 1.6 \mathrm{~g} / \mathrm{L} \\
\mathrm{CO}_{2} \\
\text { Placebo group: } \\
1.6 \mathrm{~g} / \mathrm{L} \mathrm{CO}_{2}\end{array}$ & $\begin{array}{l}\text { Bath } \\
20 \text { min } \\
15 \text { times } \\
4 \text { weeks } \\
\mathrm{T}=35^{\circ} \mathrm{C} \\
\text { Additional: } \\
\text { Physiotherapy } \\
\text { Occupational therapy } \\
\text { Galvanic bathes } \\
\text { (3/week) } \\
\text { Classic massage }\end{array}$ & $\begin{array}{l}\text { Endpoints: } \\
\text { Pain intensity (VAS) } \\
\text { Keitel functional Test } \\
\text { (KFI) } \\
\text { Arthritis Impact } \\
\text { Measurement (AIMS) } \\
\text { Timepoints: } \\
\text { Before and directly } \\
\text { after therapy, as well } \\
\text { as, } 3 \text { and } 6 \text { months } \\
\text { after therapy. }\end{array}$ & $\begin{array}{l}\text { Pain intensity decreased in } \\
\text { both groups, radon } \\
\text { treatment results in a } \\
\text { significant and longer lasting } \\
\text { benefit from pain relief; } \\
\text { KFI more in radon group; } \\
\text { AIMS score was significantly } \\
\text { increased in radon treated } \\
\text { patients up to } 6 \text { months; } \\
\text { KFI score shows a not } \\
\text { significant benefit in radon } \\
\text { treated patients }\end{array}$ & [98] \\
\hline $\begin{array}{l}\text { Van Tubergen et al., } \\
2001\end{array}$ & $\begin{array}{l}\text { Prospective; } \\
\text { different treatment } \\
\text { groups at different } \\
\text { places. }\end{array}$ & $\begin{array}{c}120 \text { patients AS } \\
\text { (40 spa with radon, } \\
40 \text { spa w/o radon } \\
40 \text { physical therapy } \\
\text { at home) }\end{array}$ & $\begin{array}{l}\text { Radon group: } \\
0.536 \text { WLM } \\
\text { Placebo group: } \\
\text { Thermal water + } \\
\text { sauna } \\
\text { Hydrotherapy } \\
\text { Bathing } \\
\text { Sports }\end{array}$ & $\begin{array}{l}\text { Gallery / inhalation } \\
\text { Each } 1 \mathrm{~h} \\
16 \text { times } \\
3 \text { weeks } \\
\mathrm{T}=38-41^{\circ} \mathrm{C} \\
\text { Additional: } \\
\text { Physical exercise } \\
\text { Postural correction } \\
\text { therapy }\end{array}$ & $\begin{array}{l}\text { Endpoints: } \\
\text { BASFI } \\
\text { Well-being VAS } \\
\text { Pain intensity VAS } \\
\text { Morning stiffness } \\
\text { Timepoints: } \\
\text { Before therapy } \\
\text { After therapy week 4, } \\
\text { 16, 28, and } 40\end{array}$ & $\begin{array}{l}\text { Primary goals borderline } \\
\text { significant; } \\
\text { pooled index of change } \\
\text { shows highly significant } \\
\text { differences as well as } \\
\text { long-lasting effects of radon } \\
\text { compared to conventional } \\
\text { treatment }\end{array}$ & [105] \\
\hline
\end{tabular}


Table 3. Cont.

\begin{tabular}{|c|c|c|c|c|c|c|c|}
\hline $\begin{array}{c}\text { First Author } \\
\text { Year of Publication }\end{array}$ & Trial Design & $\begin{array}{l}\text { Patient Number } \\
\text { Indication }\end{array}$ & Dose & $\begin{array}{c}\text { Type of Exposure } \\
\text { Frequency } \\
\text { Duration }\end{array}$ & $\begin{array}{l}\text { Endpoints and } \\
\text { Timepoints }\end{array}$ & Most Important Findings & Ref. \\
\hline Yamaoka et al., 2004 & Prospective & $\begin{array}{c}15 \text { people } \\
\text { (putative healthy } \\
\text { individuals) }\end{array}$ & $\begin{array}{l}\text { Radon group: } \\
2080 \mathrm{~Bq} / \mathrm{m}^{3} \\
\text { Sauna Group: } \\
54 \mathrm{~Bq} / \mathrm{m}^{3} \\
\text { Control Group: } \\
54 \mathrm{~Bq} / \mathrm{m} 3\end{array}$ & $\begin{array}{l}\text { Inhalation } \\
40 \text { min } \\
5 \text { times } \\
\mathrm{T}_{\text {Radon }}=36^{\circ} \mathrm{C} \\
\mathrm{T}_{\text {Sauna }}=48^{\circ} \mathrm{C} \\
\mathrm{T}_{\text {Control }}=36^{\circ} \mathrm{C}\end{array}$ & $\begin{array}{l}\text { Endpoints: } \\
\text { SOD } \\
\text { AOC } \\
\text { lipid metabolism } \\
\text { CD4/CD8 immune } \\
\text { cells } \\
\text { vasoactive substances } \\
\text { diabetes-associated } \\
\text { markers } \\
\text { Timepoints: } \\
\text { Blood draw before and } \\
\text { at } 2 \text { h after each } \\
\text { treatment. In addition, } \\
5 \text { and } 10 \text { days after } \\
\text { treatment. }\end{array}$ & $\begin{array}{l}\text { Significant increase in SOD } \\
\text { as well as decrease of lipid } \\
\text { metabolism and cholesterol } \\
\text { at } 10 \text { days for radon and } \\
\text { sauna group; } \\
\text { radon enhances T cell } \\
\text { activity significantly, while } \\
\text { sauna has similar effects, } \\
\text { only significant at } 10 \text { days } \\
\text { after treatment; } \\
\text { radon enhances the CD4 T } \\
\text { cell amount significantly } \\
\text { after treatment, while CD8 T } \\
\text { cells were decreased, } \\
\text { respectively; } \\
\text { radon group shows } \\
\text { significantly more endorphin } \\
\text { and a reduced vasopression }\end{array}$ & [112] \\
\hline Yamaoka et al., 2004 & Prospective & 20 patients $\mathrm{OA}$ & $\begin{array}{l}\text { Radon group: } \\
2080 \mathrm{~Bq} / \mathrm{m}^{3} \\
\text { non-controlled }\end{array}$ & $\begin{array}{l}\text { Inhalation } \\
40 \text { min each } \\
\text { Every } 2 \text { days } \\
\mathrm{T}=42{ }^{\circ} \mathrm{C}\end{array}$ & $\begin{array}{l}\text { Endpoints: } \\
\text { SOD, catalase, lipid } \\
\text { peroxide, total } \\
\text { cholesterol, GSH, } \\
\beta \text {-endorphin, ACTH, } \\
\text { uric acid, ANP, } \\
\text { and vasopressin levels } \\
\text { in blood } \\
\text { Timepoints: } \\
\text { Before therapy, } 2 \text { h, 2, } \\
4 \text { and } 6 \text { weeks after } \\
\text { therapy }\end{array}$ & $\begin{array}{l}\text { SOD activity is significantly } \\
\text { and long-lasting increased; } \\
\text { Catalase activity is } \\
\text { significantly increased after } \\
4 \text { and } 6 \text { weeks; } \\
\text { T cells of CD4 type are } \\
\text { increased, while CD8 T cells } \\
\text { are decreased from } 2 \text { to } \\
4 \text { weeks after therapy; } \\
\beta \text {-endorphin and anti-ANP } \\
\text { levels were significantly and } \\
\text { long-lasting increased after } \\
\text { therapy; } \\
\text { Vasopressin was } \\
\text { significantly and } \\
\text { long-lasting decreased; } \\
\text { Cholesterol and lipid } \\
\text { peroxide levels were } \\
\text { significantly and } \\
\text { long-lasting decreased }\end{array}$ & [113] \\
\hline
\end{tabular}


Table 3. Cont.

\begin{tabular}{|c|c|c|c|c|c|c|c|}
\hline $\begin{array}{c}\text { First Author } \\
\text { Year of Publication }\end{array}$ & Trial Design & $\begin{array}{l}\text { Patient Number } \\
\text { Indication }\end{array}$ & Dose & $\begin{array}{c}\text { Type of Exposure } \\
\text { Frequency } \\
\text { Duration }\end{array}$ & $\begin{array}{l}\text { Endpoints and } \\
\text { Timepoints }\end{array}$ & Most Important Findings & Ref. \\
\hline Shehata et al., 2006 & Retrospective & $\begin{array}{c}83 \text { patients AS } \\
\text { (radon treatment) } \\
10 \text { patients AS } \\
\text { (conv. Treatment) } \\
10 \text { patients LBP }\end{array}$ & $\begin{array}{l}\text { Radon group: } \\
\sim 4.5 \mathrm{nCi} / 1 \\
\text { Placebo groups: } \\
\text { Convent. Therapy }\end{array}$ & $\begin{array}{l}\text { Gallery/ inhalation } \\
1 \text { h each } \\
\mathrm{T}=38-41^{\circ} \mathrm{C} \\
9-12 \text { times } \\
\text { 3-4 weeks } \\
\text { Additional: } \\
\text { Physiotherapy } \\
\text { Hydrotherapy } \\
\text { Massage } \\
\text { Exercises }\end{array}$ & $\begin{array}{l}\text { Endpoint: } \\
\text { TGF- } \beta \text { (total and active } \\
\text { form) } \\
\text { Timepoint: } \\
\text { Before, during and } \\
\text { after the treatment }(\sim 0 \text {, } \\
2 \text { and } 4 \text { weeks)- }\end{array}$ & $\begin{array}{l}\text { Total TGF- } \beta \text { level increased } \\
\text { significantly in radon } \\
\text { exposed patients compared } \\
\text { to conventional treated } \\
\text { patients or LBP controls; } \\
\text { active TGF- } \beta \text { increased } \\
\text { strongly and significantly in } \\
\text { radon exposed patients } \\
\text { compared to conventional } \\
\text { treated patients or LBP } \\
\text { controls; } \\
\text { therapy responders show an } \\
\text { inverse correlation with CRP } \\
\text { concentration }\end{array}$ & [107] \\
\hline Franke et al., 2007 & $\begin{array}{l}\text { Prospective; } \\
\text { blinded; } \\
\text { randomized }\end{array}$ & $\begin{array}{c}134 \text { patients RA } \\
\text { (67 patients per } \\
\text { group) }\end{array}$ & $\begin{array}{l}\text { Radon group: } \\
1.1 \mathrm{kBq} / \mathrm{L}, 1.3 \mathrm{~g} / \mathrm{L} \\
\mathrm{CO}_{2} \\
\text { Placebo group: } \\
1.6 \mathrm{~g} / \mathrm{L} \mathrm{CO}_{2}\end{array}$ & $\begin{array}{l}\text { Baths } \\
20 \text { min } \\
15 \text { times } \\
3 \text { weeks } \\
\mathrm{T}=35^{\circ} \mathrm{C} \\
\text { Additional: } \\
\text { Physiotherapy } \\
\text { Occupational therapy } \\
\text { Galvanic bathes } \\
\text { (3/week) } \\
\text { Swedish massage }\end{array}$ & $\begin{array}{l}\text { Endpoints: } \\
\text { pain intensity, } \\
\text { pain frequency, } \\
\text { morning stiffness, } \\
\text { functional capacity (all } \\
\text { VAS), Drug intake } \\
\text { Timepoints: } \\
\text { Before and after last } \\
\text { treatment, 3, 6, 9, } \\
\text { and } 12 \text { months after } \\
\text { treatment }\end{array}$ & $\begin{array}{l}\text { Drug intake was } \\
\text { significantly reduced from } \\
\text { month } 9 \text { on; } \\
\text { both groups had treatment } \\
\text { effects, most not significant; } \\
\text { repeated measurement } \\
\text { ANCOVA revealed } \\
\text { significant and long-lasting } \\
\text { enhanced quality of life due } \\
\text { to fewer limitations induced } \\
\text { by pain }\end{array}$ & [99] \\
\hline Moder et al., 2010 & Prospective & 33 AS patients & $\begin{array}{l}\text { Radon group: } \\
\sim 4.5 \mathrm{nCi} / \mathrm{L} \\
\text { non-controlled }\end{array}$ & $\begin{array}{l}\text { Gallery/ inhalation } \\
90 \text { min each } \\
10 \text { times } \\
3 \text { weeks } \\
37-40.5^{\circ} \mathrm{C}\end{array}$ & $\begin{array}{l}\text { Endpoints: } \\
\text { Disease activity, } \\
\text { BASDAI. BASFI, } \\
\text { BASMI } \\
\text { serum concentration of } \\
\text { RANKL, OPG, TNF } \alpha \text {, } \\
\text { TGF- } \beta \text {, IL-17, IL-6 } \\
\text { Timepoints: } \\
\text { Before and after } \\
\text { therapy ( } 3 \text { weeks) }\end{array}$ & $\begin{array}{l}\text { Disease-associated scores } \\
\text { BASDAI. BASFI, BASMI } \\
\text { decreased significantly after } \\
\text { therapy; } \\
\text { serum conc. of TGF- } \beta 1, \text { IL-6, } \\
\text { TNF- } \alpha \text {, RANKL, OPG, } \\
\text { as well as OPG/RANKL } \\
\text { ratio was significantly } \\
\text { increased; } \\
\text { active form of TGF- } \beta, \text { IL-6, } \\
\text { TNF } \alpha \text {. }\end{array}$ & [106] \\
\hline
\end{tabular}


Table 3. Cont.

\begin{tabular}{|c|c|c|c|c|c|c|c|}
\hline $\begin{array}{l}\text { First Author } \\
\text { Year of Publication }\end{array}$ & Trial Design & $\begin{array}{l}\text { Patient Number } \\
\text { Indication }\end{array}$ & Dose & $\begin{array}{c}\text { Type of Exposure } \\
\text { Frequency } \\
\text { Duration }\end{array}$ & $\begin{array}{l}\text { Endpoints and } \\
\text { Timepoints }\end{array}$ & Most Important Findings & Ref. \\
\hline $\begin{array}{l}\text { Franke et al., } 2013 \\
\text { (IMuRa Trial) }\end{array}$ & $\begin{array}{l}\text { Prospective; } \\
\text { blinded; } \\
\text { randomized; } \\
\text { multicentric }\end{array}$ & $\begin{array}{l}652 \text { Patients } \\
\text { BP } 437 \text { pts. } \\
\text { OA } 230 \text { pts. } \\
\text { RA } 98 \text { pts. } \\
\text { AS } 39 \text { pts. } \\
\text { Multi } 146 \text { pts. }\end{array}$ & $\begin{array}{l}\text { Radon group } \\
\text { (332 patients) } \\
\text { Radon bathes } \\
\text { according to } \\
\text { specific center } \\
\text { (with or without } \\
\mathrm{CO}_{2} \text { ) } \\
\text { or } \\
\text { Radon } \\
\text { Speleotherapy } \\
\text { Control group: } \\
\text { (320 patients) } \\
\text { Placebo bathes } \\
\text { according to } \\
\text { specific center } \\
\text { (either tap water or } \\
\text { non-radon- } \\
\text { containing } \\
\text { fountain, with or } \\
\text { without } \mathrm{CO}_{2} \text { ) }\end{array}$ & $\begin{array}{l}\text { Bath } \\
20 \text { min } \\
12 \text { times } \\
3-4 \text { weeks } \\
\mathrm{T}=36-38{ }^{\circ} \mathrm{C}\end{array}$ & $\begin{array}{l}\text { Endpoints: } \\
\text { Pain intensity (VAS) } \\
\text { Pain Questionnaire } \\
\text { Functional capacity } \\
\text { (FFbH) } \\
\text { Western Ontario } \\
\text { questionnaire } \\
\text { (WOMAC) } \\
\text { Health assessment } \\
\text { questionnaire (HAQ) } \\
\text { BASFI } \\
\text { Drug intake } \\
\text { Timepoints: } \\
\text { Before and after last } \\
\text { treatment, 3, 6, } \\
\text { and } 9 \text { month after } \\
\text { treatment }\end{array}$ & $\begin{array}{l}\text { Radon treatment leading to } \\
\text { significant and long-lasting } \\
\text { relieve of self-assessed pain } \\
\text { (VAS); } \\
\text { OA and BP patients have the } \\
\text { strongest and most lasting } \\
\text { benefit from radon } \\
\text { treatment, while OA patients } \\
\text { seem to additionally have an } \\
\text { enhanced quality of living } \\
\text { up to } 6 \text { months after } \\
\text { treatment }\end{array}$ & {$[76]$} \\
\hline $\begin{array}{l}\text { Dischereit et al., } 2014 \\
\text { (Article in german) }\end{array}$ & Prospective & $\begin{array}{l}24 \text { patients RA } \\
24 \text { patients OA }\end{array}$ & $\begin{array}{l}\text { Radon group } \\
44 \mathrm{kBq} / \mathrm{m}^{3} \\
\text { non-controlled }\end{array}$ & $\begin{array}{l}\text { Gallery/ inhalation } \\
60 \text { min each } \\
12 \text { times } \\
3 \text { weeks } \\
\mathrm{T}=37.5-41^{\circ} \mathrm{C}\end{array}$ & $\begin{array}{l}\text { Endpoints: } \\
\text { Pain intensity and } \\
\text { duration } \\
\text { Disease activity and } \\
\text { functional score } \\
\text { (BASDAI; BAS-G) } \\
\text { Serum levels of } \\
\text { RANKL, OPG, } \\
\text { and TNF- } \alpha \\
\text { Timepoints: } \\
\text { Directly before and } \\
\text { after therapy, as well as } \\
3 \text { months after therapy }\end{array}$ & $\begin{array}{l}\text { Pain was relieved after } \\
\text { therapy and after } 3 \text { months } \\
\text { in AS patients and after } \\
3 \text { months in OA patients; } \\
\text { BASDAI was reduced } \\
\text { significantly, } \\
\text { and long-lasting in AS } \\
\text { patients; } \\
\text { TNF- } \alpha \text { level was decreased } \\
\text { in both groups, significantly } \\
\text { in OA; RANKL level was } \\
\text { significantly decreased in } \\
\text { both groups, OPG increased } \\
\text { only in AS; } \\
\text { RANKL/OPG ratio } \\
\text { decreased only AS } \\
\text { significantly }\end{array}$ & [108] \\
\hline
\end{tabular}


Table 3. Cont.

\begin{tabular}{|c|c|c|c|c|c|c|c|}
\hline $\begin{array}{c}\text { First Author } \\
\text { Year of Publication }\end{array}$ & Trial Design & $\begin{array}{l}\text { Patient Number } \\
\text { Indication }\end{array}$ & Dose & $\begin{array}{c}\text { Type of Exposure } \\
\text { Frequency } \\
\text { Duration }\end{array}$ & $\begin{array}{l}\text { Endpoints and } \\
\text { Timepoints }\end{array}$ & Most Important Findings & Ref. \\
\hline $\begin{array}{l}\text { Winklmayr et al., } \\
2015\end{array}$ & $\begin{array}{l}\text { Prospective; } \\
\text { blinded; } \\
\text { randomized }\end{array}$ & $\begin{array}{c}64 \text { healthy } \\
\text { individuals } \\
\text { Married partners }\end{array}$ & $\begin{array}{l}\text { Radon group } \\
412-900 \mathrm{~Bq} / \mathrm{L}, \\
\text { Placebo: } \\
\text { thermal water }\end{array}$ & $\begin{array}{l}\text { Bath } \\
20 \text { min } \\
5 \text { times }+3 \text { times brush } \\
\text { up } \\
\mathrm{T}=36-39{ }^{\circ} \mathrm{C} \\
\text { Additional: } \\
\text { Mountain hiking } 3-4 \mathrm{~h} \\
\text { daily }\end{array}$ & $\begin{array}{l}\text { Endpoints: } \\
\text { Serum conc. OPG, } \\
\text { RANKL, } \\
\text { OPG/RANKL ratio } \\
\text { Timepoints: } \\
\text { Day } 0,6,60 \text {, } \\
\text { and } 63 \text { and } 6 \text { months } \\
\text { after last treatment }\end{array}$ & $\begin{array}{l}\text { Treatment benefits were seen } \\
\text { in both groups in OPG, } \\
\text { RANKL, and OPG/RANKL } \\
\text { ratio; } \\
\text { detected borderline } \\
\text { significant trend towards } \\
\text { bigger effect in Radon } \\
\text { treated group }\end{array}$ & [114] \\
\hline $\begin{array}{l}\text { Lange et al., } 2016 \text { and } \\
\qquad 2012\end{array}$ & \multirow[b]{2}{*}{ Prospective } & \multirow[b]{2}{*}{$\begin{array}{l}25 \text { patients RA } \\
24 \text { patients OA }\end{array}$} & \multirow[b]{2}{*}{$\begin{array}{l}\text { Radon group } \\
4.5 \mathrm{nCi} / 1 \\
\text { non-controlled }\end{array}$} & \multirow{2}{*}{$\begin{array}{l}\text { Gallery / inhalation } \\
60 \text { min each } \\
12 \text { times } \\
3 \text { weeks } \\
\mathrm{T}=37.5-41^{\circ} \mathrm{C}\end{array}$} & $\begin{array}{l}\text { Endpoints: } \\
\text { serum conc. RANKL, } \\
\text { OPG, TNF- } \alpha \text {, } \\
\text { and ACPA } \\
\text { Timepoints: } \\
\text { Directly before and } \\
\text { after therapy }\end{array}$ & $\begin{array}{l}\text { The serum conc. of TNF } \alpha \\
\text { and RANKL levels } \\
\text { decreased in both groups; } \\
\text { only in RA patients, } \\
\text { OPG level increased, leading } \\
\text { to a decreased } \\
\text { RANKL/OPG ratio; } \\
\text { ACPA titers decreased only } \\
\text { in RA patients }\end{array}$ & {$[115,116]$} \\
\hline Lange et al., 2017 & & & & & $\begin{array}{l}\text { Endpoints: } \\
\text { Pain VAS } \\
\text { FFbH questionnaire } \\
\text { ESR } \\
\text { Serum CRP, RANKL, } \\
\text { OPG, TNF- } \alpha, \text { IL-10, } \\
\text { and ACPA } \\
\text { Timepoints: } \\
\text { Directly before and } \\
\text { after therapy, as well as } \\
3 \text { months after therapy }\end{array}$ & $\begin{array}{l}\text { RA patients have significant } \\
\text { immediate and lasting effect } \\
\text { in pain relief, while health } \\
\text { status (FFbH) is increasing; } \\
\text { OA patients have } \\
\text { significantly lasting pain } \\
\text { relief effect; } \\
\text { serum concentration of } \\
\text { IL-10 is significantly } \\
\text { increased directly after } \\
\text { treatment in RA patients }\end{array}$ & [117] \\
\hline
\end{tabular}


Table 3. Cont.

\begin{tabular}{|c|c|c|c|c|c|c|c|}
\hline $\begin{array}{c}\text { First Author } \\
\text { Year of Publication }\end{array}$ & Trial Design & $\begin{array}{l}\text { Patient Number } \\
\text { Indication }\end{array}$ & Dose & $\begin{array}{c}\text { Type of Exposure } \\
\text { Frequency } \\
\text { Duration }\end{array}$ & $\begin{array}{l}\text { Endpoints and } \\
\text { Timepoints }\end{array}$ & Most Important Findings & Ref. \\
\hline $\begin{array}{l}\text { Rühle et al., } 2017 \\
\text { (RAD-ON01) }\end{array}$ & $\begin{array}{l}\text { Prospective } \\
\text { Blinded } \\
\text { Randomized }\end{array}$ & $\begin{array}{l}100 \text { patients with } \\
\text { musculoskeletal } \\
\text { disorders } \\
50 \text { patients per group } \\
\text { Ambulant patients }\end{array}$ & $\begin{array}{l}\text { Radon group } \\
1200 \mathrm{~Bq} / \mathrm{L}, \text { Radon } \\
\text { water only group); } \\
\mathrm{Radon} / \mathrm{CO}_{2} \text { group } \\
600 \mathrm{~Bq} / \mathrm{L} \text { and } 1 \mathrm{~g} / 1 \\
\mathrm{CO}_{2} ; \\
\text { Radon- } \mathrm{CO}_{2} \text {-group } \\
\text { Covered bath-tube }\end{array}$ & $\begin{array}{l}\text { Bath } \\
20 \text { min each } \\
9 \text { times } \\
3 \text { weeks } \\
\mathrm{T}=35^{\circ} \mathrm{C}\end{array}$ & $\begin{array}{l}\text { Endpoints: } \\
\text { Immune modulation } \\
\text { via DIoB [100] method } \\
\text { Pain relief (VAS and } \\
\text { questionnaire) } \\
\text { Pain sensitivity } \\
\text { (dolorimetry, pressure } \\
\text { point measurement) } \\
\text { Timepoints: } \\
\text { Directly before as well } \\
\text { as } 6,12 \text {, and } 30 \text { weeks } \\
\text { after therapy }\end{array}$ & $\begin{array}{l}\text { Long-lasting and significant } \\
\text { pain reduction until end of } \\
\text { observation period in whole } \\
\text { trial population; } \\
\text { significant and long-lasting } \\
\text { increase in T cells and } \\
\text { monocytes; } \\
\text { significant temporarily } \\
\text { increase of dendritic cells } \\
\text { and regulatory T cells; } \\
\text { significant and long-lasting } \\
\text { reduction of the expression } \\
\text { of the activation marker } \\
\text { CD69 on T, B, and NK cells }\end{array}$ & [104] \\
\hline $\begin{array}{l}\text { Cucu et al., } 2017 \\
\text { (RAD-ON01) }\end{array}$ & & & & & $\begin{array}{l}\text { Endpoints: } \\
\text { Amount of regulatory } \\
\text { T cells } \\
\text { Serum markers of bone } \\
\text { and lipid metabolism }\end{array}$ & $\begin{array}{l}\text { significant and long-lasting } \\
\text { decrease of collagen } \\
\text { fragments (CTX-I) and } \\
\text { reduced levels of visfatin. } \\
\text { Both factors are correlating } \\
\text { significantly with pain } \\
\text { intensity (VAS); } \\
\text { regulatory T cells increase } \\
\text { significantly and } \\
\text { long-lasting after treatment }\end{array}$ & [102] \\
\hline
\end{tabular}


Table 3. Cont.

\begin{tabular}{|c|c|c|c|c|c|c|c|}
\hline $\begin{array}{l}\text { First Author } \\
\text { Year of Publication }\end{array}$ & Trial Design & $\begin{array}{l}\text { Patient Number } \\
\text { Indication }\end{array}$ & Dose & $\begin{array}{c}\text { Type of Exposure } \\
\text { Frequency } \\
\text { Duration }\end{array}$ & $\begin{array}{l}\text { Endpoints and } \\
\text { Timepoints }\end{array}$ & Most Important Findings & Ref. \\
\hline $\begin{array}{l}\text { Rühle et al., } 2018 \\
\text { (RAD-ON01) }\end{array}$ & & & & & $\begin{array}{l}\text { Endpoints: } \\
\text { Pain relief (VAS and } \\
\text { questionnaire) } \\
\text { Pain sensitivity } \\
\text { (dolorimetry, pressure } \\
\text { point measurement) } \\
\text { Blood pressure } \\
\text { Antioxidative capacity } \\
\text { (AOC) } \\
\text { Superoxiddis-mutase } \\
\text { (SOD) }\end{array}$ & $\begin{array}{l}\text { Long-lasting and significant } \\
\text { pain reduction until the end } \\
\text { of the observation period in } \\
\text { whole trial population, } \\
\text { Radon } \mathrm{CO}_{2} \text { bathes show a } \\
\text { trend to be less effective } \\
\text { (n.s.); } \\
\text { lowered blood pressure in } \\
\text { both groups, nightly } \\
\text { measured systolic and } \\
\text { diastolic blood pressure } \\
\text { significantly decreased in } \\
\text { Radon/CO treated patients; } \\
\text { SD-VLF decreased } \\
\text { significantly after radon } \\
\text { therapy; } \\
\text { SOD2 reduced significantly } \\
6 \text { weeks after treatment and } \\
\text { increased significantly } \\
\text { long-lasting }\end{array}$ & [103] \\
\hline $\begin{array}{l}\text { Kullmann et al., } 2018 \\
\text { (RAD-ON01) }\end{array}$ & & & & & $\begin{array}{l}\text { Endpoints: } \\
\text { Detection of } \\
\text { inflammatory and } \\
\text { anti-inflammatory } \\
\text { cytokines in serum of } \\
\text { patients. }\end{array}$ & $\begin{array}{l}\text { No significant effects found } \\
\text { for TNF } \alpha \text {, IL- } 1 \beta \text {, IFN } \gamma \text {, IL-18, } \\
\text { IL-1Ra, IL-10 concentration } \\
\text { in serum of the patients; } \\
\text { TGF- } \beta \text { concentration was } \\
\text { significantly increased after } \\
\text { treatment and significantly } \\
\text { correlates with pain } \\
\text { sensitivity; } \\
\text { IL-18 level corresponds with } \\
\text { lowered pain perception }\end{array}$ & [101] \\
\hline
\end{tabular}

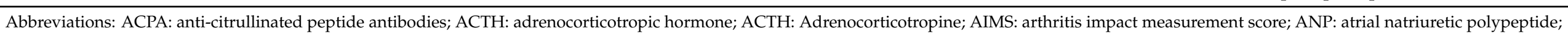

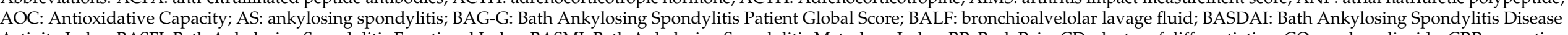

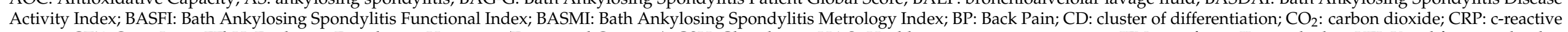

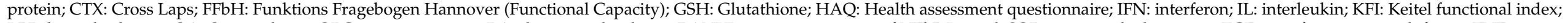

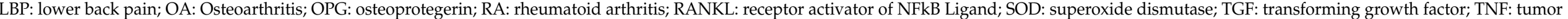
necrosis factor; VAS: Visual Analog Scale; WOMAC: Western Ontario questionnaire. Bold letters highlight the trial groups, additional treatments, trial endpoints, and timepoints of investigation. 


\subsection{Biomedical Investigations in Patients}

In addition to the evaluation of pain or functionality of joints, the biomedical investigations reviewed in the following paragraph revealed treatment-induced changes of the immune status and release of specific factors. These are cytokines, hormones and growth factors, which are known to influence pain perception, inflammation, bone metabolism and the cardiovascular system.

One putative key player associated with pain reduction is the anti-inflammatory cytokine transforming growth factor beta 1 (TGF)- $\beta 1$. Indications come from patient studies, all not blinded and without control groups. In AS patients undergoing combined radon speleotherapy and exercise treatment, an increase of serum levels of both, the precursor and activated TGF- $\beta 1$ was detected directly after therapy while this was not the case for lower back pain patients [ $n=83$, prospective study] [107]. For a subgroup of "responders" [ $n=48$ ], a correlation of morning stiffness and decreased C-reactive protein (CRP) level was observed directly after therapy, suggesting that the pain reducing effect of TGF- $\beta 1$ is based on a reduction of inflammation [108]. A comparable increment in the serum levels of active TGF- $\beta 1$ was found directly after therapy for different treatment modalities and diseases, i.e., in the serum of AS patients [ $n=33$ ] after radon speleotherapy [106] and six weeks after radon balneotherapy, in a larger cohort of patients $[n=100]$, suffering from non-rheumatic, musculoskeletal diseases (MSD) [101].

Studies on $\beta$-endorphin, another important signaling protein, are also pointing to a reduced pain perception after radon treatment. Levels of $\beta$-endorphin were found to be increased directly after radon speleotherapy in OA patients $[n=15$, control group: sauna] [113] and slightly (not significant) in patients with chronic respiratory diseases [ $n=81]$ [118].

In addition, inflammation, which is likely to be a cause of pain, was investigated. Regardless of a chronic or acute inflammatory status of the patients before treatment, low serum levels of the pro-inflammatory cytokines tumor necrosis factor (TNF)- $\alpha$, interleukin (IL)-1 $\beta$, interferon (IFN)- $\gamma$ and IL-18 were detected. For example, despite low basal TNF- $\alpha$ levels, they further decreased significantly in OA and RA patients after combined radon and HT treatment [OA: $n=48$, balneotherapy [108]; RA: $n=49$, speleotherapy [116]; sample collection directly after therapy]. A clear anti-inflammatory effect in RA patients was confirmed in one of these studies based on the levels of ACPA (Anti-citrullinated protein antibodies) along with inflammatory cytokines and pain reduction [116]. In contrast, for AS patients, the TNF- $\alpha$ decrease was less pronounced as reported in the study of Dischereit and co-workers [108].

Decreased serum levels of IL-18 were observed in MSD patients [mostly OA, $n=100$ ] directly after radon balneotherapy and correlated with reduced pain perception [101]. However, only a trend was observed, and the treatment was radon exposure alone, suggesting that the anti-inflammatory effect is relatively weak and becomes more pronounced in combination with HT. This idea is endorsed by the results of a study performed in AS patients for radon and HT- speleotherapy [ $n=33]$, where disease scores were improved and TGF- $\beta 1$ was increased [106]. A weak point of this study is that the serum levels were measured only directly after exposure.

The studies as mentioned above, however, all have to be interpreted with care as they were non-blinded and mainly lack control groups. In line with that, a potential causal relationship of $\beta$-endorphin and TGF- $\beta 1$ levels remains to be elucidated. However, increasing evidence is provided for treatment-induced changes in the immune status of the patients. In an earlier study with a low number of patients enrolled $[n=15]$ a combined treatment with radon and HT was compared to HT alone. Proliferation of CD4+ T-helper cells was increased after ex vivo stimulation, whereas the response to stimulation with concanavalin A of CD8+ cytotoxic T-cells was decreased. Both effects were lasting until the end of therapy (10 days) only in the radon-HT-group, but not in the group receiving HT only [112]. The interpretation of these treatment-induced changes is difficult, as there are not enough data on the interaction of immune cells. More recently, a broader view of 
the immune status of MSD patients was provided in the frame of a larger study where a detailed immune phenotyping was performed after radon balneotherapy $[n=100$, RADON-01 study]. While the large immune cell classes such as B-cells or T-cells remained almost unaffected, the results suggest transient anti-inflammatory and immune inhibiting effects. For example, mostly immune-suppressive regulatory T cells (Treg) were increased up to 12 weeks in the complete cohort [104]. In addition, Treg levels that were investigated in a smaller subgroup of this large cohort remained increased over the whole observation period of 30 weeks, whereas the amount of immune-stimulating T helper cells (Th17) was not changed [102]. In addition, common activation markers like CD69 and HLA-DR were altered and stayed upregulated (HLA-DR) or downregulated (CD69) during the observation period.

Since radon-treated patients reported improvements in mobility, diagnostic markers for bone formation (OPG, osteoprotegerin) and bone resorption (RANKL, receptor activator of nuclear factor kappa $b$ ligand) were studied. A positive influence of a combined radon and HT-balneotherapy on bone metabolism was investigated in a randomized and blinded trial. This trial enrolled postmenopausal women who were healthy but at risk for developing osteoporosis [ $n=64$, randomized, blinded, controlled]. A control group received regular water bathes; both groups underwent regular physical exercise. A slight increase of the OPG/RANKL ratio was observed in both treatment groups, lasting up to two months only after radon treatment, indicating enhanced bone formation and/or reduced bone resorption. However, these changes, along with the observed increase of other markers for bone formation (osteocalcin and osteopontin), cannot be attributed to radon treatment alone because of the combination with enhanced physical exercise during treatment [114]. In AS and OA patients, hints for changes in bone metabolism were obtained in studies without physical exercise, after combined radon and HT speleotherapy treatment. RANKL serum levels were significantly decreased in these patients directly after therapy [ $n=48$ ] [108]. In a second study, the same authors report similar results for RA patients in combination with decreased disease activity and functional restriction, and increased spine mobility score directly after therapy [117]. Taken together, for AS and RA patients, the indications for reduced bone resorption and, in some cases, enhanced bone formation are reported $[119,120]$. In line with the above-mentioned weaker effect reported for MSD (mostly OA) patients [ $n=32$ ], no significant alterations of RANKL and OPG after radon balneotherapy were found for up to 30 weeks after therapy. However, a reduced bone resorption can be assumed because collagen fragments (CTX-I) in serum samples were significantly lower during the 30-week period of biomedical follow-up [102].

In the following, some smaller studies are reviewed in order to highlight single observations concerning adipokines related to chronic inflammation, pain-related stress hormones, antioxidative capacity, and the cardiovascular and central nervous system. Those findings, substantiated by most studies, may contribute to clarify the mechanism of action of radon therapy after verification in larger patient cohorts.

Some hormones, i.e., leptin and visfatin, are typically released by the adipose tissue and play a role in the pathogenesis of chronic inflammatory bone diseases [121]. Changes of these adipokines after radon treatment were recently published [102]. Following radon balneotherapy alone, visfatin levels were found to be significantly reduced over the observation period of 30 weeks in MSD (mostly OA) patients [102]. One of the aforementioned studies [114], where radon balneotherapy or bathes in normal water were combined with physical exercise, revealed decreased leptin levels, concomitantly with increased osteocalcin levels.

Pain is a stressor activating the hypothalamic-pituitary-adrenal-thyroid-gonadal (HPATG) system, which includes hormones like cortisol, insulin, thyroid hormones, or adrenal corticotropin hormone (ACTH) [122]. Reduced activation of these signaling molecules could be an indirect indication of a modified pain perception. A couple of studies were conducted, most of them for a combined treatment with radon and HT. Accordingly, the specific effect of radon treatment cannot be discriminated from these investigations yet. 
Two studies with radon speleotherapy revealed that serum levels of insulin [ $n=15]$ [112] and ACTH $[n=20]$ [113] were increased for OA patients, directly or two weeks after therapy, respectively. A decreased activation was found for thyroid hormones directly following radon speleotherapy alone, mostly in male patients with chronic respiratory diseases [ $n=81]$ [112]. The treatment-induced changes in the regulation of these hormones may imply a role in the response to radon therapy, although analyses were restricted to short periods after the end of treatment only.

Also, after combined radon and HT balneotherapy, but in combination with physical exercise and in healthy individuals, adrenocorticotropic hormone (ACTH) was decreased over the course of follow-up of 6 months, [ $n=53$, blinded, randomized, placebo controlled]. In addition, a long-lasting decrease of parathyroid hormone (PTH) serum levels in both treatment groups (HT balneotherapy with or without radon) was reported. PTH indirectly stimulates osteoclast activity in bones [114], indicating an additional reason for the putative decrease of bone resorption after treatment.

Hints for a beneficial impact of radon therapy on the cardiovascular system were also reported. In the RAD-ON-01 balneotherapy study, all patients had lowered blood pressure, a long-term relaxation effect and decreased heart rate variability. These effects indicate a modulation of the sympathetic nervous system and a relaxation of smooth muscles in the cardiovascular system [103]. In a study of OA patients [ $n=20]$, atrial natriuretic peptide (ANP), a vasodilator, was increased after speleotherapy [113], whereas vasopressin, a vasoconstrictor, was decreased [123], which could explain the effects.

Indications for an enhanced antioxidative capacity were obtained in two studies. One study showed, for combined radon and HT speleotherapy, a decreased lipid peroxide and cholesterol level, while superoxide dismutase (SOD) was increased in both treatment groups directly after treatment $[n=15]$ [112], indicating an enhanced antioxidative capacity. In MSD patients [ $n=100$, RAD-ON-01], the SOD levels were decreased at early time points (6 weeks), but increased later after radon balneotherapy [103], emphasizing the importance of longitudinal assessments of treatment-induced changes.

\subsection{Animal Studies}

Although radon therapy is in therapeutic use for decades, preclinical studies on underlying mechanisms are scarce and restricted to the last 20 years. The few studies available will be summarized in this paragraph. The review, however, will exclude lung cancer studies, performed in rats after radon exposure [124] because these investigations highlight the effects of chronic exposure.

Although well conducted, the design of most studies investigating non-cancer effects of radon treatment challenges their relevance for the impact of patient treatment. No animal studies are available investigating the effects of the typical exposure situations, such as radon bathing or using animal models for the main indications of radon therapy, i.e., rheumatoid arthritis and Morbus Bechterew. Furthermore, the experimental design of these studies hardly overlaps with treatment conditions. Nevertheless, some basic information about the activation of antioxidative mechanisms can be inferred from these studies. In some of the disease models, an enhanced SOD activity and higher t-GSH levels in the blood and different organs were found [125-128], which is in line with the measurements in OA patients mentioned above $[103,112]$. Interestingly, an enhanced antioxidative activity was also observed in healthy mice $[129,130]$, thus pointing to a more general mechanistic feature of radon exposure. 
Using a polyarthritic mouse model to investigate the clinical effects of radon exposure, ongoing experiments investigate the underlying mechanisms and their potential correlation to radon exposure. In the same mouse model, beneficial effects of low dose radiotherapy with photons have already been reported [131]. Furthermore, experiments to test the effect of radon on chronic inflammatory skin diseases, i.e., psoriasis in a mouse model, are performed. Notably, for treatment of psoriasis, no animal or valid patient studies are published up to now, although the disease covers an indication for radon spas and speleotherapies (see Table 4). However, in one animal study, the impact of radon exposure on atopic dermatitis, which also covers an indication for radon treatment, is assessed [132]. The authors reported significantly lowered severity score of the skin lesions, together with a lower immunoglobulin E (IgE) level after radon treatment. Importantly, these beneficial effects were only found after pre-treatment with radon prior to skin sensitization with picrylchloride, indicating a protective rather than a curing effect of radon treatment. From a mechanistic point of view, this is endorsed by other animal studies (Table 4), where radon treatment was also started before disease induction. 
Table 4. Animal studies with radon.

\begin{tabular}{|c|c|c|c|c|c|c|c|c|}
\hline $\begin{array}{l}\text { First Author Year } \\
\text { of Publication }\end{array}$ & Species & Group Size & $\begin{array}{l}\text { Type of Treatment } \\
\text { and Dose }\end{array}$ & $\begin{array}{l}\text { Time of Analysis } \\
\text { after Exposure }\end{array}$ & Disease Model & Endpoints & $\begin{array}{l}\text { Most Important } \\
\text { Findings }\end{array}$ & Ref. \\
\hline $\begin{array}{l}\text { Takahashi et al., } \\
2006\end{array}$ & $\begin{array}{c}\text { Mice } \\
\text { (SPF NC/Nga, } \\
\text { female, } 5 \text { weeks) } \\
\text { Mice (C57BL/6, } \\
\text { male, } 6 \text { weeks) }\end{array}$ & $n=4-9$ & $\begin{array}{l}\text { Drinking water; } \\
203 \mathrm{~Bq} / \mathrm{L} ; \\
\text { approximate amount } \\
\text { of radon ingested by } \\
\text { each mouse } 140-176, \\
68-85 \text { and } \\
0.86-1.08 \mathrm{~Bq} / \mathrm{kg} \text { week }\end{array}$ & Up to 4 weeks & $\begin{array}{l}\text { Atopic dermatitis } \\
\text { model: } \\
\text { sensitization with } \\
5 \% \text { purified } \\
\text { picrylchloride } \\
\text { Lung metastasis } \\
\text { model: injection of } \\
\text { B16 melanoma } \\
\text { cells } \\
\text { (both } 2 \text { weeks after } \\
\text { start of radon } \\
\text { treatment) }\end{array}$ & $\begin{array}{l}\text { Atopic dermatitis: } \\
\text { Skin severity score, } \\
\text { Plasma IgE } \\
\text { Lung metastasis: } \\
\text { number of } \\
\text { metastasis }\end{array}$ & $\begin{array}{l}\text { Lower skin } \\
\text { severity score and } \\
\text { lower plasma IgE, } \\
\text { only after radon } \\
\text { pretreatment, } \\
\text { Lower number of } \\
\text { lung metastasis } \\
\text { only after radon } \\
\text { pretreatment and } \\
\text { small number of } \\
\text { inoculated tumor } \\
\text { cells }\end{array}$ & [132] \\
\hline $\begin{array}{l}\text { Kataoka et al., } \\
2011\end{array}$ & $\begin{array}{l}\text { Mice (BALB/c, male, } \\
\text { 7-8 weeks, } 25 \mathrm{~g})\end{array}$ & $\begin{array}{c}n=5(\text { Exp.3) } \\
n=4-7(\text { Exp. } 4) \\
n=5-6(\text { Exp.5) }\end{array}$ & $\begin{array}{l}\text { Exp.3: inhalation for } \\
24 \mathrm{~h}, 4000 \mathrm{~Bq} / \mathrm{m}^{3} \\
\text { Exp: } 4600 \text { and } \\
3500 \mathrm{~Bq} / \mathrm{m}^{3} \\
\text { Exp.5: } 180 \mathrm{~Bq} / \mathrm{m}^{3} \text { for } \\
6 \mathrm{~h}\end{array}$ & $\begin{array}{l}\text { Exp.3: directly } \\
\text { Exp.4: } 4 \mathrm{~h} \\
\text { Exp.5: } 24 \mathrm{~h}\end{array}$ & $\begin{array}{l}\text { Alcohol-induced } \\
\text { oxidative damage; } \\
\mathrm{CCl}_{4} \text {-induced } \\
\text { hepathopathy }\end{array}$ & $\begin{array}{l}\text { SOD activity } \\
\text { Catalase activity } \\
\text { ALD-activity and } \\
\text { t-GSH in brain } \\
\text { and liver }\end{array}$ & $\begin{array}{l}\text { Protective effect of } \\
\text { radon on } \\
\text { oxidative damage }\end{array}$ & [126] \\
\hline $\begin{array}{l}\text { Kataoka et al., } \\
2011\end{array}$ & $\begin{array}{l}\text { Mice }(\text { BALB / c, male, } \\
7 \text { weeks, } 25 \mathrm{~g})\end{array}$ & $n=4-6$ & $\begin{array}{l}\text { Inhalation, } \\
18 \mathrm{kBq} / \mathrm{m}^{3} \text { for } 6 \mathrm{~h}\end{array}$ & $24 \mathrm{~h}$ & $\begin{array}{c}\mathrm{CCl}_{4} \text {-induced } \\
\text { hepatic and renal } \\
\text { damage }\end{array}$ & $\begin{array}{l}\text { t-GSH content, } \\
\text { lipid peroxide } \\
\text { levels, and GPx } \\
\text { and GR activity in } \\
\text { liver and kidney } \\
\text { GOT, GPT, } \\
\text { ALP activity, CRE, } \\
\text { and T-CHO in } \\
\text { serum }\end{array}$ & $\begin{array}{l}\text { Radon inhalation } \\
\text { inhibits oxidative } \\
\text { damage of liver } \\
\text { and kidney }\end{array}$ & [125] \\
\hline
\end{tabular}


Table 4. Cont.

\begin{tabular}{|c|c|c|c|c|c|c|c|c|}
\hline $\begin{array}{l}\text { First Author Year } \\
\text { of Publication }\end{array}$ & Species & Group Size & $\begin{array}{c}\text { Type of Treatment } \\
\text { and Dose }\end{array}$ & $\begin{array}{l}\text { Time of Analysis } \\
\text { after Exposure }\end{array}$ & Disease Model & Endpoints & $\begin{array}{l}\text { Most Important } \\
\text { Findings }\end{array}$ & Ref. \\
\hline $\begin{array}{c}\text { Kataoka et al., } \\
2011\end{array}$ & $\begin{array}{l}\text { Mice }(\text { BALB / c, male, } \\
7 \text { weeks, } 25 \mathrm{~g})\end{array}$ & $n=5$ & $\begin{array}{l}\text { Inhalation, } 250,500, \\
1000,2000, \\
\text { or } 4000 \mathrm{~Bq} / \mathrm{m}^{3} \text { for } 0.5 \text {, } \\
1,2,4, \text { or } 8 \text { days }\end{array}$ & Directly & Healthy & $\begin{array}{l}\text { SOD activity in } \\
\text { brain, lung, } \\
\text { thymus, heart, } \\
\text { liver, stomach, } \\
\text { pancreas, kidney }\end{array}$ & $\begin{array}{l}\text { Activation of SOD; } \\
\text { in plasma, brain, } \\
\text { and lung strong } \\
\text { and rapid } \\
\text { response } \\
\text { (enhancement); in } \\
\text { liver, heart, } \\
\text { pancreas, } \\
\text { and small intestine } \\
\text { only after low and } \\
\text { high } \\
\text { concentrations; in } \\
\text { thymus and } \\
\text { kidney after low } \\
\text { concentration; no } \\
\text { change in stomach }\end{array}$ & [129] \\
\hline $\begin{array}{l}\text { Kataoka et al., } \\
2012\end{array}$ & $\begin{array}{c}\text { Mice } \\
\text { (ICR, female, } \\
8 \text { weeks, } 28 \mathrm{~g} \text { ) }\end{array}$ & $n=5-8$ & $\begin{array}{l}\text { Inhalation, } 1000 \text { or } \\
2000 \mathrm{~Bq} / \mathrm{m}^{3} \text { for } 24 \mathrm{~h} \\
\text { or }(\mathrm{L}(+) \text {-ascorbic acid } \\
\text { injection or DL- } \alpha \text { - } \\
\text { tocopherol injection }\end{array}$ & $24 \mathrm{~h}$ & $\begin{array}{l}\mathrm{CCl}_{4} \text {-induced } \\
\text { hepathopathy }\end{array}$ & $\begin{array}{l}\text { SOD activity, } \\
\text { catalase activity, } \\
\text { GPx activity, } \\
\text { t-GSH, LP levels } \\
\text { and TG in the } \\
\text { liver; GOT, } \\
\text { GPT activity, } \\
\text { TG and T-CHO } \\
\text { levels in the } \\
\text { serum; and } \\
\text { histological } \\
\text { examination of } \\
\text { liver tissue }\end{array}$ & $\begin{array}{l}\text { Decreased } \\
\text { activities of GOT } \\
\text { and GPT in serum; } \\
\text { decreased TG } \\
\text { levels in liver } \\
\text { significantly } \\
\text { higher SOD, } \\
\text { catalase and GPx } \\
\text { activity in livers; } \\
\text { radon inhalation } \\
\text { has an } \\
\text { antioxidative } \\
\text { effect against } \\
\text { CCl4-induced } \\
\text { hepatopathy that } \\
\text { is comparable to } \\
\text { treatment with AA } \\
\text { or } \\
\alpha \text {-tocopherol }\end{array}$ & [127] \\
\hline
\end{tabular}


Table 4. Cont.

\begin{tabular}{|c|c|c|c|c|c|c|c|c|}
\hline $\begin{array}{c}\text { First Author Year } \\
\text { of Publication }\end{array}$ & Species & Group Size & $\begin{array}{l}\text { Type of Treatment } \\
\text { and Dose }\end{array}$ & $\begin{array}{l}\text { Time of Analysis } \\
\text { after Exposure }\end{array}$ & Disease Model & Endpoints & $\begin{array}{l}\text { Most Important } \\
\text { Findings }\end{array}$ & Ref. \\
\hline $\begin{array}{l}\text { Kataoka et al., } \\
2012\end{array}$ & $\begin{array}{c}\text { Mice } \\
\text { (ICR, female, } \\
8 \text { weeks, } 28 \mathrm{~g} \text { ) }\end{array}$ & $n=5-8$ & $\begin{array}{l}\text { Inhalation, } 1000 \text { or } \\
2000 \mathrm{~Bq} / \mathrm{m}^{3} \text { for } 24 \mathrm{~h} \\
\text { or DL- } \alpha \text {-tocopherol } \\
\text { injection different } \\
\text { concentrations) }\end{array}$ & $24 \mathrm{~h}$ & $\begin{array}{l}\mathrm{CCl}_{4} \text {-induced } \\
\text { hepathopathy }\end{array}$ & $\begin{array}{l}\text { SOD, catalase, } \\
\text { t-GSH, and LP in } \\
\text { kidneys CRE level } \\
\text { in serum, }\end{array}$ & $\begin{array}{l}\text { Decrease of CRE } \\
\text { an LP levels; } \\
\text { radon inhalation } \\
\text { has an } \\
\text { antioxidative } \\
\text { effect comparable } \\
\text { to the treatment } \\
\text { with } \alpha \text {-tocopherol } \\
\text { at a dose of } \\
300-500 \mathrm{mg} / \mathrm{kg} \\
\text { weight }\end{array}$ & [133] \\
\hline $\begin{array}{l}\text { Kataoka et al., } \\
2012\end{array}$ & $\begin{array}{c}\text { Mice } \\
\text { (ICR, female, } \\
8 \text { weeks, } 28 \text { g) }\end{array}$ & $n=6-7$ & $\begin{array}{l}\text { Inhalation, } \\
2000 \mathrm{~Bq} / \mathrm{m}^{3} \text { for } 24 \mathrm{~h}\end{array}$ & $2 \mathrm{~h}$ & $\begin{array}{c}\text { Carrageenan- } \\
\text { induced } \\
\text { inflammatory paw } \\
\text { edema }\end{array}$ & $\begin{array}{l}\text { SOD activity, } \\
\text { catalase activity, } \\
\text { t-GSH content, } \\
\text { LP levels, TNF- } \alpha \text {, } \\
\text { NO, and paw } \\
\text { histology. }\end{array}$ & $\begin{array}{l}\text { Paw volume } \\
\text { significantly } \\
\text { decreased; lower } \\
\text { TNF- } \alpha \text { and NO } \\
\text { levels; SOD } \\
\text { activity increased; } \\
\text { fewer infiltrating } \\
\text { leukocytes; } \\
\text { increased SOD } \\
\text { and catalase } \\
\text { activities }\end{array}$ & [134] \\
\hline $\begin{array}{l}\text { Nishiyama et al., } \\
2012\end{array}$ & $\begin{array}{c}\text { Mice } \\
\text { (BALB/c, male, } \\
7 \text { weeks, } 23 \text { g) }\end{array}$ & $n=8$ & $\begin{array}{l}\text { Inhalation, } \\
2000 \mathrm{~Bq} / \mathrm{m}^{3} \text { for } 8 \text { days }\end{array}$ & Directly & $\begin{array}{l}\text { Dextran sulfate } \\
\text { sodium (DSS) } \\
\text { model of colitis } \\
\text { (while radon } \\
\text { exposure) }\end{array}$ & $\begin{array}{l}\text { MPO, NO, TNF- } \alpha \text {, } \\
\text { SOD, CAT, t-GSH), } \\
\text { LPO level, } \\
\text { and Histology, } \\
\text { DAI and weight } \\
\text { gain }\end{array}$ & $\begin{array}{l}\text { Significant lower } \\
\text { DAI score; less } \\
\text { shortened colon; } \\
\text { lower plasma } \\
\text { TNF- } \alpha \text { and MPO } \\
\text { activity in colon; } \\
\text { enhanced SOD } \\
\text { activity and tGSH } \\
\text { content; lower } \\
\text { LPO level in the } \\
\text { colon and NO } \\
\text { level in plasma }\end{array}$ & [135] \\
\hline
\end{tabular}


Table 4. Cont

\begin{tabular}{|c|c|c|c|c|c|c|c|c|}
\hline $\begin{array}{l}\text { First Author Year } \\
\text { of Publication }\end{array}$ & Species & Group Size & $\begin{array}{l}\text { Type of Treatment } \\
\text { and Dose }\end{array}$ & $\begin{array}{l}\text { Time of Analysis } \\
\text { after Exposure }\end{array}$ & Disease Model & Endpoints & $\begin{array}{l}\text { Most Important } \\
\text { Findings }\end{array}$ & Ref. \\
\hline Toyota et al., 2012 & $\begin{array}{c}\text { Mice } \\
\text { (C57BL } / 6 \mathrm{~J}, \text { male, } \\
8 \text { weeks, } 20 \mathrm{~g} \text { ) }\end{array}$ & $n=4-6$ & $\begin{array}{l}\text { Inhalation, } \\
4000 \mathrm{~Bq} / \mathrm{m}^{3} \text { for } 24 \mathrm{~h}\end{array}$ & 6 and $24 \mathrm{~h}$ & $\begin{array}{c}\text { Acute } \\
\text { alcohol-induced } \\
\text { hepatopathy }\end{array}$ & $\begin{array}{l}\text { SOD, catalase, } \\
\text { t-GSH, GPx, GR, } \\
\text { TG, and lipid } \\
\text { peroxide in liver, } \\
\text { GOT and GPT, } \\
\text { activity and the } \\
\text { TG, T-CHO in } \\
\text { serum }\end{array}$ & $\begin{array}{l}\text { Radon treatment } \\
\text { activates } \\
\text { antioxidative } \\
\text { functions and } \\
\text { inhibits acute } \\
\text { alcohol-induced } \\
\text { oxidative damage, } \\
\text { hepatopathy and } \\
\text { fatty liver in mice }\end{array}$ & [136] \\
\hline $\begin{array}{c}\text { Nishiyama et al., } \\
2013\end{array}$ & $\begin{array}{c}\text { Mice, (C57BL/6J, } \\
\text { male, } 9 \text { weeks, } \\
\text { 25-28 g) }\end{array}$ & $n=5-8$ & $\begin{array}{l}\text { Inhalation, 1000, 2500, } \\
\text { and } 5500 \mathrm{~Bq} / \mathrm{m} 3 \text { for } \\
24 \mathrm{~h}\end{array}$ & 4 days & $\begin{array}{l}\text { Streptozotocin- } \\
\text { induced } \\
\text { Type-1 Diabetes } \\
\text { (after radon } \\
\text { exposure) }\end{array}$ & $\begin{array}{l}\text { SOD activity, } \\
\text { CAT activity, } \\
\text { t-GSH content, } \\
\text { LPO, blood } \\
\text { glucose, serum } \\
\text { insulin, and body } \\
\text { weight }\end{array}$ & $\begin{array}{l}\text { Higher SOD } \\
\text { activity and t-GSH } \\
\text { content, lower } \\
\text { LPO levels; } \\
\text { significantly } \\
\text { suppressed blood } \\
\text { glucose elevation } \\
\text { and body weight } \\
\text { decrease; higher } \\
\text { serum insulin; } \\
\text { radon inhalation } \\
\text { partially } \\
\text { suppressed } \\
\text { type-1 diabetes } \\
\text { induced by STZ } \\
\text { administration }\end{array}$ & [137] \\
\hline Yamato et al., 2013 & $\begin{array}{c}\text { Mice } \\
\text { (male ICR, } 8 \text { weeks, } \\
38 \mathrm{~g} \text { ) }\end{array}$ & $n=5-10$ & $\begin{array}{l}\text { Inhalation, } 1000 \text { or } \\
2000 \mathrm{~Bq} / \mathrm{m}^{3} \text { for } 24 \mathrm{~h}\end{array}$ & $\begin{array}{c}\text { Up to } 35 \mathrm{~min} \\
\text { (licking response), } \\
\text { no information for } \\
\text { other endpoints }\end{array}$ & $\begin{array}{l}\text { Formalin-induced } \\
\text { transient } \\
\text { inflammatory pain }\end{array}$ & $\begin{array}{l}\text { licking response } \\
\text { (pain), TNF- } \alpha, \mathrm{NO}, \\
\text { paw histology, } \\
\text { SOD and CAT } \\
\text { activities, total } \\
\text { glutathione } \\
\text { (t-GSH) content, } \\
\text { and LPO levels }\end{array}$ & $\begin{array}{l}\text { Enhanced } \\
\text { SOD-activity, } \\
\text { t-GSH content in } \\
\text { serum and paws, } \\
\text { reduced number } \\
\text { of leukocytes, } \\
\text { reduced TNF- } \alpha \\
\text { and NO level }\end{array}$ & [138] \\
\hline
\end{tabular}


Table 4. Cont.

\begin{tabular}{|c|c|c|c|c|c|c|c|c|}
\hline $\begin{array}{c}\text { First Author Year } \\
\text { of Publication }\end{array}$ & Species & Group Size & $\begin{array}{c}\text { Type of Treatment } \\
\text { and Dose }\end{array}$ & $\begin{array}{l}\text { Time of Analysis } \\
\text { after Exposure }\end{array}$ & Disease Model & Endpoints & $\begin{array}{l}\text { Most Important } \\
\text { Findings }\end{array}$ & Ref. \\
\hline Etani et al., 2016 & $\begin{array}{c}\text { Mice } \\
\text { (male, } 8 \text { weeks, } \\
\text { 32-38 g) }\end{array}$ & $\begin{array}{c}n=8-9(\text { drinking } \\
\text { treatment }) \\
n=6(\text { inhalation })\end{array}$ & $\begin{array}{l}\text { Drinking water: } 338 \pm \\
11 \mathrm{~Bq} / \mathrm{L} \text { for } 2 \text { weeks } \\
\text { Inhalation: } \\
2000 \mathrm{~Bq} / \mathrm{m}^{3} \text { for } 24 \mathrm{~h}\end{array}$ & $3 \mathrm{~h}$ & $\begin{array}{l}\text { PO model of } \\
\text { hyperuricemia } \\
\text { (induced after } \\
\text { radon treatment) }\end{array}$ & $\begin{array}{l}\text { Activities of XOD, } \\
\text { SOD andCAT; } \\
\text { levels of t-GSH } \\
\text { and proteins in } \\
\text { liver and kidney }\end{array}$ & $\begin{array}{l}\text { Radon-inhalation } \\
\text { activates } \\
\text { antioxidative } \\
\text { function and } \\
\text { reduces serum } \\
\text { uric acid levels }\end{array}$ & [139] \\
\hline $\begin{array}{l}\text { Kataoka et al., } \\
2016\end{array}$ & $\begin{array}{c}\text { Mice } \\
\text { (ICR, male, } 8 \text { weeks; } \\
33-40 \mathrm{~g})\end{array}$ & $n=5-6$ & $\begin{array}{l}\text { Inhalation, } \\
1000 \mathrm{~Bq} / \mathrm{m}^{3} \text { for } 24 \mathrm{~h} \\
\text { and/or pregabalin } \\
\text { treatment. }\end{array}$ & $\begin{array}{l}30 \mathrm{~min}, 60 \mathrm{~min}, \\
90 \mathrm{~min}, 120 \mathrm{~min}\end{array}$ & $\begin{array}{l}\text { CCI-induced } \\
\text { neuropathic pain }\end{array}$ & $\begin{array}{l}\text { von Frey Test } \\
\text { (pain), } \\
\text { SOD activity, } \\
\text { catalase activity, } \\
\text { t-GSH content, } \\
\text { and LP level in } \\
\text { paw. }\end{array}$ & $\begin{array}{l}\text { Pregabalin and } \\
\text { radon has } \\
\text { mitigative effect } \\
\text { on pain after CCI } \\
\text { due to } \\
\text { antioxidative } \\
\text { function after } \\
\text { radon inhalation }\end{array}$ & [140] \\
\hline $\begin{array}{l}\text { Etani et al., } \\
\quad 2017\end{array}$ & $\begin{array}{l}\text { Mice (BALB/c, male, } \\
8 \text { weeks, 25-28 g) }\end{array}$ & $\begin{array}{c}n=8(\text { drinking } \\
\text { treatment }) \\
n=8(\text { inhalation })\end{array}$ & $\begin{array}{l}\text { Drinking water: } 663 \pm \\
36 \mathrm{~Bq} / \mathrm{L} \text { for } 2 \text { weeks } \\
\text { Inhalation: } \\
2000 \mathrm{~Bq} / \mathrm{m}^{3} \text { for } 24 \mathrm{~h}\end{array}$ & $1 \mathrm{~h}$ & $\begin{array}{l}\text { Gastric mucosal } \\
\text { injury induced by } \\
\text { oral ethanol } \\
\text { administration } \\
\text { (induced after } \\
\text { radon treatment) }\end{array}$ & $\begin{array}{l}\text { UI and HI: SOD } \\
\text { and } \\
\text { CAT activity, } \\
\text { and the levels of } \\
\text { t-GSH in stomachs }\end{array}$ & $\begin{array}{l}\text { Lower UI and IHI } \\
\text { after radon } \\
\text { treatment; } \\
\text { activation of } \\
\text { antioxidative } \\
\text { mechanisms }\end{array}$ & [141] \\
\hline $\begin{array}{l}\text { Kataoka et al., } \\
2017\end{array}$ & $\begin{array}{l}\text { Mice (BALB/c, male, } \\
8 \text { weeks, 24-28 g) }\end{array}$ & $n=7$ & $\begin{array}{l}\text { Inhalation, } \\
500-2000 \mathrm{~Bq} / \mathrm{m}^{3} \text { for } \\
24 \mathrm{~h}\end{array}$ & Unclear & Healthy & $\begin{array}{l}\text { NF- } \mathrm{kB}, \mathrm{NIK} \text {, } \\
\text { IKK- } \beta, \text { ATM; total } \\
\text { SOD, Mn-SOD } \\
\text { and } \mathrm{Cu} / \mathrm{Zn} \text {-SOD } \\
\text { activities and } \\
\text { protein levels }\end{array}$ & $\begin{array}{l}\text { Induction of SOD } \\
\text { proteins, mainly } \\
\text { Mn-SOD; } \\
\text { Mn-SOD induced } \\
\text { by NF-kB } \\
\text { activation } \\
\text { stimulated by } \\
\text { DNA damage and } \\
\text { oxidative stress }\end{array}$ & [130] \\
\hline
\end{tabular}


Table 4. Cont.

\begin{tabular}{|c|c|c|c|c|c|c|c|c|}
\hline $\begin{array}{l}\text { First Author Year } \\
\text { of Publication }\end{array}$ & Species & Group Size & $\begin{array}{c}\text { Type of } \\
\text { Treatment and } \\
\text { Dose }\end{array}$ & $\begin{array}{l}\text { Time of Analysis } \\
\text { after Exposure }\end{array}$ & Disease Model & Endpoints & $\begin{array}{l}\text { Most Important } \\
\text { Findings }\end{array}$ & Ref. \\
\hline Pei et al., 2017 & $\begin{array}{l}\text { Mice, (BALB/c, } \\
\text { male, } 15 \mathrm{~g})\end{array}$ & $n=6$ & $\begin{array}{l}\text { Inhalation, } \\
100,000 \mathrm{~Bq} / \mathrm{m}^{3} \text {, } \\
12 \mathrm{~h} / \mathrm{d} \text {, for up to } \\
\text { cumulative doses } \\
\text { of } \\
60 \mathrm{WLM}\end{array}$ & Directly & Healthy & $\begin{array}{l}\text { circRNA, H\&E, } \\
\text { Caspase } 3\end{array}$ & $\begin{array}{l}\text { Enhanced Caspase } \\
3 \text { expression, } \\
\text { circRNA profiles } \\
\text { are changed }\end{array}$ & [142] \\
\hline Paletta et al. 1975 & $\begin{array}{c}\text { Rat } \\
\text { (male, } 200 \mathrm{~g})\end{array}$ & $n=5$ & $\begin{array}{l}\text { Series 1: Rn } \\
12.5 \mathrm{nCi} / \mathrm{L}, \\
\mathrm{RaB} / \mathrm{Rn} 0,25 ; \\
\text { Series } 2: \mathrm{Rn} \\
110 \mathrm{nCi} / \mathrm{L}, \\
\mathrm{RaB} / \mathrm{Rn} 0,33 \\
\text { Different doses to } \\
\text { organs? }\end{array}$ & $12 \mathrm{~d}$ & Healthy & $\begin{array}{l}\text { Corticosteroid } \\
\text { level in serum }\end{array}$ & $\begin{array}{l}2 \text { maxima of } \\
\text { corticosteroid after } \\
\text { exposure, one after } \\
8 \mathrm{~h} \text {, one after } 5 \\
\text { (low) or } 9 \mathrm{~h} \text { (high } \\
\text { concentration) }\end{array}$ & [143] \\
\hline Taya et al., 1994 & $\begin{array}{c}\text { Rat } \\
\text { (male, } 4-6 \text { months } \\
\text { old) }\end{array}$ & $n=10-25$ & $\begin{array}{l}\text { 120-990 WLM } \\
\text { (dose rate } \\
7-9 \mathrm{WLM} / \mathrm{h} ; \\
725-770 \mathrm{~Bq} / \mathrm{m} 3 \text { ) }\end{array}$ & $7-28 \mathrm{~d}$ & Healthy & $\begin{array}{l}\text { Proliferation in } \\
\text { epithelial cells of } \\
\text { respiratory tract; } \\
\text { binucleate alveolar } \\
\text { macrophages } \\
\text { (AM) and/or } \\
\text { micronuclei }\end{array}$ & $\begin{array}{l}\text { Labelling indices } \\
\text { increased after } \\
\text { exposure; highest } \\
\text { in bronchial } \\
\text { epithelial cells; } \\
\text { binculeate AM as } \\
\text { well as induction } \\
\text { of micronuclei was } \\
\text { increased after } \\
\text { exposure; } \\
\text { binucleate AM } \\
\text { with micronuclei } \\
\text { were only induced } \\
\text { in exposed } \\
\text { animals; } \\
\text { no inflammation }\end{array}$ & [144] \\
\hline
\end{tabular}


Table 4. Cont.

\begin{tabular}{|c|c|c|c|c|c|c|c|c|}
\hline $\begin{array}{l}\text { First Author Year } \\
\text { of Publication }\end{array}$ & Species & Group Size & $\begin{array}{c}\text { Type of } \\
\text { Treatment and } \\
\text { Dose }\end{array}$ & $\begin{array}{l}\text { Time of Analysis } \\
\text { after Exposure }\end{array}$ & Disease Model & Endpoints & $\begin{array}{l}\text { Most Important } \\
\text { Findings }\end{array}$ & Ref. \\
\hline Ma et al., 1996 & $\begin{array}{c}\text { Rats } \\
\text { (Wistar, male, } \\
30 \text { weeks) }\end{array}$ & $n=3$ & $\begin{array}{l}\text { Inhalation, } \\
1000-5000 \mathrm{kBq} / \mathrm{m}^{3} \\
\text { or } \\
400-1600 \mathrm{kBq} / \mathrm{m}^{3} \\
\text { for } 4 \text { or } 16 \mathrm{~h}\end{array}$ & Directly & Healthy & $\begin{array}{l}\text { SOD activity in } \\
\text { blood, kidney, } \\
\text { spleen, and liver }\end{array}$ & $\begin{array}{l}\text { Increase after } 4 \mathrm{~h} \text {, } \\
\text { decrease after } 16 \mathrm{~h} \\
\text { of exposure }\end{array}$ & [128] \\
\hline Collier et al., 1997 & $\begin{array}{l}\text { Rats } \\
\text { (Sprague-Dawley, } \\
\text { male, 2-12 month, }\end{array}$ & $n=2-6$ & $\begin{array}{l}\text { Inhalation, } \\
\text { 200-1600 WLM, } \\
250-7142 \text { WL for } \\
\text { 1-27.5 days }\end{array}$ & $14 \mathrm{~d}$ & Healthy & $\begin{array}{l}\text { Cell number, } \\
\text { nuclear } \\
\text { abberations, } \\
\text { number of } \\
\text { macrophages and } \\
\text { macrophage } \\
\text { proliferation in } \\
\text { lung lavage fluid, } \\
\text { H\&E and BrdU } \\
\text { staining of lung } \\
\text { sections }\end{array}$ & $\begin{array}{l}\text { Positive } \\
\text { dose-response for } \\
\text { most effects }\end{array}$ & [145] \\
\hline Cui et al., 2008 & $\begin{array}{c}\text { Rats } \\
\text { (Wistar) }\end{array}$ & $n=6$ & $\begin{array}{l}\text { Inhalation; } 60,90 \text {, } \\
\text { and } 120 \text { working } \\
\text { level months } \\
\text { (WLM) in total; } \\
\text { inhalation for } 8 \mathrm{~h} \\
\text { per day, } 6 \text { days per } \\
\text { week }\end{array}$ & No information & Healthy & $\begin{array}{l}\text { MNR, hprt assay } \\
\text { in lymphocytes, } \\
\text { and tracheal- } \\
\text { bronchial } \\
\text { epithelial cells }\end{array}$ & $\begin{array}{l}\text { Dose-dependent } \\
\text { increase of MNR, } \\
\text { the mutation } \\
\text { frequency of hprt } \\
\text { is increased with } \\
\text { accumulated dose, } \\
\text { can be used as } \\
\text { biomarkers for } \\
\text { genetic changes } \\
\text { after radon } \\
\text { exposure }\end{array}$ & [146] \\
\hline $\begin{array}{c}\text { Yamaoka et al., } \\
1993\end{array}$ & Rabbits & $n=10-14$ & $\begin{array}{l}\text { Inhalation of } \\
\text { nebulized radon } \\
\text { water; } 7-10 \mathrm{kBq} / \mathrm{L} \\
\text { or } 14-18 \mathrm{kBq} / \mathrm{L}\end{array}$ & Directly and $2 \mathrm{~h}$ & Healthy & $\begin{array}{l}\text { Lipid peroxide, } \\
\text { SOD, membrane } \\
\text { fluidity in brain, } \\
\text { spleen, lung, liver } \\
\text { and serum }\end{array}$ & $\begin{array}{l}\text { Enhanced SOD } \\
\text { activity, reduced } \\
\text { lipid peroxide } \\
\text { levels }\end{array}$ & [147] \\
\hline
\end{tabular}


Table 4. Cont.

\begin{tabular}{|c|c|c|c|c|c|c|c|c|}
\hline $\begin{array}{l}\text { First Author Year } \\
\text { of Publication }\end{array}$ & Species & Group Size & $\begin{array}{c}\text { Type of } \\
\text { Treatment and } \\
\text { Dose }\end{array}$ & $\begin{array}{l}\text { Time of Analysis } \\
\text { after Exposure }\end{array}$ & Disease Model & Endpoints & $\begin{array}{l}\text { Most Important } \\
\text { Findings }\end{array}$ & Ref. \\
\hline $\begin{array}{c}\text { Kataoka et al., } \\
2014\end{array}$ & $\begin{array}{l}\text { Mongolian gerbil } \\
\text { MGS/sea, (female, } \\
8 \text { weeks, } 50 \mathrm{~g} \text { ) }\end{array}$ & $n=5-7$ & $\begin{array}{l}\text { Inhalation, } \\
2000 \mathrm{~Bq} / \mathrm{m}^{3} \text { for } \\
24 \mathrm{~h}\end{array}$ & Directly & $\begin{array}{l}\text { Transient global } \\
\text { cerebral ischemia } \\
\text { induced by } \\
\text { bilateral occlusion } \\
\text { of the common } \\
\text { carotid artery } \\
\text { ( } 3 \text { days before } \\
\text { radon treatment) }\end{array}$ & $\begin{array}{l}\text { Brain histology, } \\
\text { SOD activity, } \\
\text { CAT activity, } \\
\text { and t-GSH content } \\
\text { in the brain and } \\
\text { serum. }\end{array}$ & $\begin{array}{l}\text { Number of } \\
\text { damaged neurons } \\
\text { significantly lower; } \\
\text { increased SOD } \\
\text { activity; } \\
\text { unchanged t-GSH }\end{array}$ & [148] \\
\hline
\end{tabular}

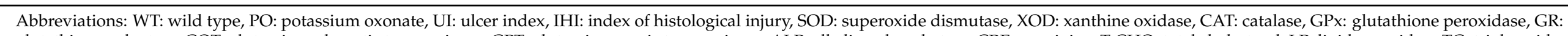

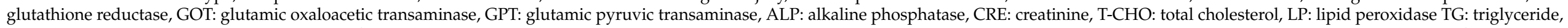

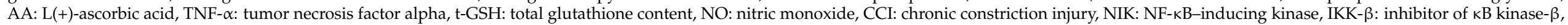
ATM: ataxia-telangiectasia mutated kinase, MPO: myeloperoxidase, DAI: disease activity index, WLM: working level months, hprt hypoxanthine phosphoribosyl transferase, MNR: micronuclei rate. 


\section{Discussion: What Do We Know So Far about the Dose Distribution and Mechanism of Action Originating from Radon Exposure and Where Are Limitations?}

When considering the physical and biological interaction of radon with the human body, large uncertainties are emerging. This is mainly due to the fact that there are only fragmentarily data available for radon distribution in the human body and on underlying biological mechanisms. For radiation protection purposes related to occupational and indoor radon exposure, knowledge of the physical characteristics and the morphometry and physiology of the respiratory tract has been combined to model dose deposition in the lung and in inner organs. Models predict that the lung equivalent dose makes up for over $95 \%$ of the effective dose, whereby over $95 \%$ of that dose is caused by progeny and less than $5 \%$ by the radon gas itself. Besides the lung, organs with a high fat content receive the highest dose due to the high radon solubility in those tissues $[1,43,63,149]$. Still, models cannot consider all variations in external environmental conditions and individual physiological factors, but can discriminate between typical exposure scenarios, leading to a more exact dose determination in individual cases. However, the experimental database for model calculations of the distribution of incorporated radon and thus energy deposition in the body are based on data obtained from just a handful of studies performed decades ago, making further investigations for a proper dose determination necessary [51,56,58]. In biokinetic models, an estimation of cancer risk is based on dose conversion factors, as specified in ICRP 137 [1]. Only recently, investigations on radon relevant for the estimation of cancer risk have restarted with state-of-the-art technologies [55,150]. Major target organs of radon exposure, i.e., lung and adipose tissue, have been confirmed $[1,31,62,63]$. However, further extension of the experimental database is still desirable to fully elucidate target tissues and organs.

In epidemiological studies, cancer risk related to chronic exposure (occupational, indoor) has been evaluated, providing data sets allowing for estimations of the lung cancer risk based on activity concentrations. These estimations are valid, but at low activity concentrations, the uncertainties are significantly high. Despite large uncertainties at low activity concentrations, a cancer risk from radon exposure cannot be denied. Albeit model approaches assuming a non-linear dose-response relationship for low radiation doses, such as 'hormesis' are discussed, but large and sufficiently powered epidemiological studies on lung cancer risk following chronic radon exposure show a linear dose-response relationship without threshold dose $[68,69,71,73]$. For non-chronic exposure scenarios that are relevant for radon therapy of chronic inflammatory diseases, epidemiological data to estimate the cancer risk are completely lacking. As pointed out the additional uncertainties especially to long-term drug intake also complicates the analysis of a reliable value for the excess risk of radon therapy by radon itself. So, there is an urgent need of prospective and quality-controlled trials to analyze these hypotheses. In spite of this, a high number of patients expose themselves to radon, because they experience a benefit from the treatment. The therapeutic efficacy of radon therapy to ameliorate the symptoms of patients with chronic, degenerative and painful diseases is significant and the major goals are achieved, i.e., higher mobility and pain alleviation $[76,98,99]$. Thus, it is reasonable to assume, but not proven that the ratio of risk and benefit related to a radon therapy is different for the patients compared to healthy individuals.

Besides the above-mentioned uncertainties for the distribution and thus dose application of radon in the human body and the associated risk, radon is used for decades for the therapy of inflammatory diseases. In view of these uncertainties, the discussion about radon application in patients with chronic diseases will continue. In line with that, there is an urgent need for more quality controlled clinical trials for radon treatment to obtain a higher level of evidence as well to obtain reliable data on the risk of radon itself in therapeutic application. For example, the level of evidence for the efficiency of radon bathes was set to a moderate level in the Cochrane report by Verhagen et al. [93]. For radon balneotherapy an effective blinding is possible reducing the patients' bias. Newly designed trials should always include safety analyses to get a balanced view on this type of treatment 
(risk-benefit-analyses). Currently, two major trials are running addressing many of the above- mentioned problems:

(I) The RAD-ON02 trial (EudraCT: 2016-002085-31; DRKS00016019) according to the German drug law was started in 2018 and covers molecular and osteoimmunological analyses correlated to pain relief as well as safety issues of the patients treated in radon bathes. The final analysis of this placebo-controlled, blinded, and randomized trial is anticipated for late 2021 [151].

(II) The radon register trial of Austria was started in 2017 to cover the procedures and effects of many patients as a European basis for upcoming multicenter trials [152].

However, in contrast to the efficacy of a radon treatment, a scientific basis for the causative relationship between beneficial effects of radon treatment and the concomitant radiation exposure is still needed. In this review, we aimed at summarizing the current knowledge on putative underlying mechanisms and causal relationships, thereby highlighting hypothesis and preliminary versus established results. According to the results on biomedical investigations reported in this review, we suggest a multifactorial effect of radon exposure on the course of the disease in radon exposed patients. This is illustrated in Figure 2:

(1) Trigger of the antioxidative defence by increased superoxide dismutase (SOD) and catalase activities.

(2) Inhibition of the local and systemic inflammatory processes by increased release of TGF- $\beta 1$ along with reduced TNF- $\alpha$ levels.

(3) Decreased activation of immune cells and shift of the ratio of immune cells towards a more anti-inflammatory state.

(4) Alterations in bone metabolism resulting in diminished bone erosion.

(5) Enhanced bone formation and pain release are mediated by hormones.

The primary route of radon intake is inhalation. Inhaled radon daughter nuclei attach to the epithelial surface and radon is distributed via diffusion and active transport to different organs. The main target organ therefore is the lung, but in bone marrow and fat tissue radon daughter nuclides also accumulate. In view of the clinical application and the biomedical results obtained in patients also the musculoskeletal system has to be considered. In MSD, bone and structures of the joints are affected by erosion or resorption, often accompanied by inflammatory processes [153]. It is plausible to assume that cellular reactive oxygen species (ROS) production is part of the pathogenesis of many of the diseases treated with radon, because it is followed by an inflammatory reaction, characterized i.e., by enhanced production of TNF- $\alpha$ and other cytokines [154,155]. For example, in MSD patients, TNF- $\alpha$ is involved in recruiting OC progenitors to sites of inflammation [156], as to the joints, resulting in an increased bone resorption. According to measurements in the serum of patients, the antioxidative defense is activated, i.e., SOD is increased after radon treatment (Figure 2; arrow 1) [103], which was also reported in animal studies [141]. ROS levels are difficult to measure directly, but the above-mentioned findings indicate a reduction after radon exposure. A concomitant reduction of the levels of pro-inflammatory cytokines such as TNF- $\alpha$ was reported in some patient studies (e.g., $[108,116])$. Remarkably one potential antagonist of TNF- $\alpha$ is the pleiotropic cytokine TGF- $\beta 1$, which can also be activated by ROS [157]. In the types of diseases treated with radon this cytokine can either foster a pro-inflammatory immune reaction by inducing the differentiation of $\mathrm{T}$ cells into Th17 cells, together with IL-6 [158-160]; or, in contrast, lead to an up-regulation of anti-inflammatory Treg cells (Figure 2; arrow 2). As can be expected, TGF- $\beta 1$ levels were found to be increased [101,107], and the ratio between Th17 and Treg cells was changed in the serum of patients upon radon balneotherapy, the latter mainly due to an increase of the amount of Treg cells [102,104], which possibly attenuates the inflammatory reaction and may also inhibit osteoclast activity [131]. 


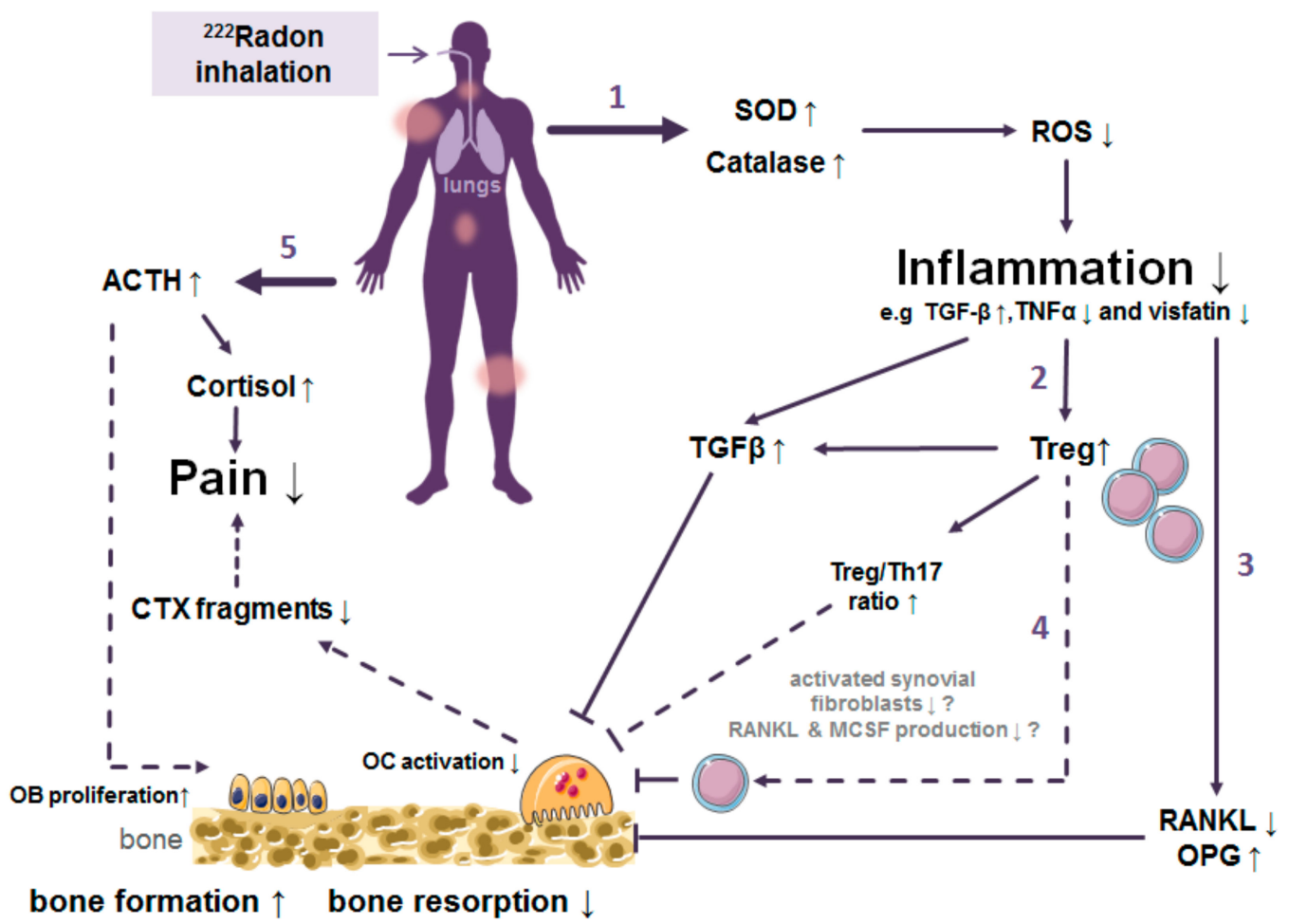

Figure 2. Proposed mechanism of action when radon is used to treat patients with a treatment for chronic musculoskeletal diseases (mostly ankylosing spondylitis, osteoarthritis or rheumatoid arthritis). Findings from in vitro or patient studies have been combined in this graph, where a solid line represents experimental findings (-) and a dashed line indicates a hypothetical relationship (- - -). Please see the text for a more detailed discussion and the explanation of the proposed mechanisms (indicated by the numbered arrows). Abbreviations: ACTH Adrenocorticotropic hormone; CTX collagen fragments type I; OC osteoclasts; IL interleukin; RANKL receptor activator of nuclear factor- $\mathrm{kB}$ ligand; OPG osteoprotegerin; ROS reactive oxygen species; SOD superoxide dismutase; TGF transforming growth factor; $\downarrow$ means decrease, while $\uparrow$ means increase. Illustrations based on pictures from Smart Servier Medical Art under the Creative Commons Attribution 3.0, France.

In joints of patients suffering from autoimmune bone diseases, activated Th17 cells and also pro-inflammatory synovial fibroblasts produce the growth factors RANKL and MCSF, leading to an increased OC differentiation and bone resorption [156]. A decrease of RANKL release, most likely associated with a reduction of bone resorption by OC, has been shown after radon treatment of RA patients (Figure 2; arrow 3) [116] and is claimed also for AS patients [106]. Not only via the RANKL/MCSF axis, but also by an increased proportion of Treg cells, triggered by the aforementioned elevated TGF- $\beta$ levels, bone resorption is impacted (Figure 2; arrow 4). This could probably be due to direct interaction of Treg cells with OC precursors via IL-4, IL-10, and TGF- $\beta 1$ as well as cytotoxic T-lymphocyte-associated protein 4 (CTLA4)-signaling, shown in murine cells [156]. In the same line of evidence, in patient studies, the RANKL-antagonist OPG was found to be enhanced after radon balneotherapy. This finding supports the proposed reduction of bone erosion in MSD (mostly OA) patients [102,108,114,116]. Additionally, pathological bone erosion seems to be counteracted after radon treatment by new bone formation, which could be caused by a stimulating effect of radon therapy on ACTH production and an upregulation of cortisol. As a consequence, pain is reduced, and osteoblast proliferation is promoted (Figure 2; arrow 5) [112,114,161].

\section{Conclusions}

In summary, experimental research on the effects of radon exposure is needed on multiple levels. For risk assessment related to different exposure scenarios including therapeutic application, the estimations of organ doses and mechanisms of intake and 
elimination of radon and its progeny have to be underpinned with more solid experimental measurements. The clinical applications have to be further analyzed in high quality and placebo-controlled trials, accompanied by biomedical investigations, to increase the level of evidence of the therapy as well as for assessment of potential side effects. This will help not only the patients directly in enhancing their mobility, but also might have a positive socioeconomic effect for an aging population.

Author Contributions: Writing—review and editing, A.M., J.W., F.R. (Felicitas Rapp), F.P., F.R. (Franz Rödel), S.H., U.S.G., G.K., C.F., B.F. All authors have read and agreed to the published version of the manuscript.

Funding: This research was funded by Bundesministerium für Bildung und Forschung, grant number 02NUK050A, 02NUK050E, 02NUK050F, 02NUK050D, Gastein Research Institute (FOI) grant number FOI-15/08-031WIE, EURADON e.V., Oberfrankenstiftung grant number P05594_K02091 and Bayerisches Staatsministerium für Gesundheit und Pflege im Rahmen des Förderprogramms zur Steigerung der medizinischen Qualität in den bayerischen Kurorten und Heilbädern (KuHeMo), grant number GE9-2499-KuHeMo-18-V3.

Institutional Review Board Statement: Not applicable.

Informed Consent Statement: Not applicable.

Data Availability Statement: Not applicable.

Conflicts of Interest: The authors declare no conflict of interest. The funders had no role in the design of the study; in the collection, analyses, or interpretation of data; in the writing of the manuscript, or in the decision to publish the results.

\section{Appendix A}

Table A1. Some of today's radon spas all over the World $[87,88,90,162]$.

\begin{tabular}{cc}
\hline Country & Place (City) \\
\hline Austria & Bad Gastein, Bad Hofgastein, Bad Zell, Gasteiner Heilstollen \\
\hline Bulgaria & Hisarja \\
\hline Czech Republic & Jáchymov \\
\hline Chile & Jahucl Hot Springs \\
\hline China & Nanshui, Taishan \\
\hline France & Plombiers \\
\hline Germany & Bad Brambach, Bad Kreuznach, Bad Münster am Stein, Bad Schlema, \\
Bad Steben, Sibyllenbad, Menzenschwand St. Blasien, Weissenstadt \\
\hline Greece & Ikaria, Polichnitos, Eftalou \\
\hline Hungary & Abaliget Cave, Budapest, Beke Cave, Eger, lstván Cave, Tapolca Hospital \\
Cave, Szemlöhegy Cave
\end{tabular}

\section{References}

1. ICRP. Occupational intake of radionuclides: Part 3. ICRP Publication 137. Ann. ICRP 2017, 46, 1-486. [CrossRef] 
2. Avrorin, V.V.; Krasikova, R.N.; Nefedov, V.D.; Toropova, M.A. The chemistry of radon. Russ. Chem. Rev. 1982, 51, 12-20. [CrossRef]

3. Lederer, C.M.; Shirley, V.S. Table of Isotopes, 7th ed.; John Wiley \& Sons: New York, NY, USA, 1978.

4. Seilnacht, T.; Binder, H. Lexikon der Chemischen Elemente; Hirzel Verlag: Stuttgart/Leipzig, Germany, 1999.

5. Rutherford, E.; Owens, R.B. Thorium and uranium radiation. Trans. R. Soc. Can. 1899, 2, 9-12.

6. Rutherford, E. A radioactive substabce emitted from thorium compounds. Philos. Mag. 1900, 5, 1-14. [CrossRef]

7. Curie, P.; Curie, M. Sur La Radioactivité Provoquée Par Les Rayons De Becquerel; Comptes Rendus Hebdomadaires des Séances de l'Académie des Sciences; Gauthier-Villars: Paris, France, 1899; pp. 714-716.

8. Dorn, E. Über die von radioaktiven Substanzen ausgesandte Emanation. Abhandel Naturforsch. Ges. 1901, 23, 1-15.

9. Debierne, A. Sur La Radioactivité Induite Provoquée Par Les Sels D'actinium; Comptes Rendus Hebdomadaires des Séances de l'Académie des Sciences; Gauthier-Villars: Paris, France, 1903; pp. 446-449.

10. Ramola, R.C.; Prasad, M.; Kandari, T.; Pant, P.; Bossew, P.; Mishra, R.; Tokonami, S. Dose estimation derived from the exposure to radon, thoron and their progeny in the indoor environment. Sci. Rep. 2016, 6, 31061. [CrossRef]

11. Committee on the Biological Effects of Ionizing Radiation (BEIR V). Health Effects of Exposure to Low Levels of Ionizing Radiation: BEIR V; Acadamies Press: Washington, DC, USA, 1990; Volume 5.

12. Tollefsen, T.; Cinelli, G.; Bossew, P.; Gruber, V.; De Cort, M. From the European indoor radon map towards an atlas of natural radiation. Radiat. Prot. Dosim. 2014, 162, 129-134. [CrossRef]

13. Doi, K.; Tokonami, S.; Yonehara, H.; Yoshinaga, S. A simulation study of radon and thoron discrimination problem in case-control studies. J. Radiat. Res. 2009, 50, 495-506. [CrossRef]

14. World Health Organization. WHO Handbook on Indoor Radon: A Public Health Perspective; World Health Organization: Geneva, Switzerland, 2009.

15. United Nations Scientific Committee on the Effects of Atomic Radiation (UNSCEAR). Sources and Effects of Ionizing Radiation: Sources; United Nations Publications: New York, NY, USA, 2000; Volume 1.

16. Harley, J.H. Radioactive emissions and radon. Bull. N. Y. Acad. Med. 1981, 57, 883.

17. Amanat, B.; Kardan, M.; Faghihi, R.; Pooya, S.H. Comparative Measurements of Radon Concentration in Soil Using Passive and Active Methods in High Level Natural Radiation Area (HLNRA) of Ramsar. J. Biomed. Phys. Eng. 2013, 3, 139.

18. Andelman, J.B. Human exposures to volatile halogenated organic chemicals in indoor and outdoor air. Environ. Health Perspect. 1985, 62, 313. [CrossRef]

19. Vogiannis, E.; Niaounakis, M.; Halvadakis, C. Contribution of 222 Rn-bearing water to the occupational exposure in thermal baths. Environ. Int. 2004, 30, 621-629. [CrossRef]

20. Lettner, H.; Hubmer, A.; Rolle, R.; Steinhäusler, F. Occupational exposure to radon in treatment facilities of the radon-spa Badgastein, Austria. Environ. Int. 1996, 22, 399-407. [CrossRef]

21. Council, N.R. Risk Assessment of Radon in Drinking Water; National Academies Press: Washington, DC, USA, 1999.

22. Sarenio, O. Leitfaden zur Messung von Radon, Thoron und ihren Zerfallsprodukten, Veröffentlichungen der Strahlenschutzkommission. Bundesminist. für Umw. Nat. Reakt. 2002. Available online: https://www.ssk.de/SharedDocs/Publikationen/ VeroeffentlichungenderSSK/Band_47.html (accessed on 23 October 2020).

23. Porstendörfer, J.; Reineking, A. Indoor behaviour and characteristics of radon progeny. Radiat. Prot. Dosim. 1992, 45, 303-311. [CrossRef]

24. Castleman, A., Jr. Consideration of the chemistry of radon progeny. Environ. Sci. Technol. 1991, 25, 730-735. [CrossRef]

25. Porstendörfer, J. Physical parameters and dose factors of the radon and thoron decay products. Radiat. Prot. Dosim. 2001, 94, 365-373. [CrossRef]

26. Porstendörfer, J.; Röbig, G.; Ahmed, A. Experimental determination of the attachment coefficients of atoms and ions on monodisperse aerosols. J. Aerosol Sci. 1979, 10, 21-28. [CrossRef]

27. Smerajec, M.; Vaupotič, J. Nanoaerosols including radon decay products in outdoor and indoor air at a suburban site. J. Toxicol. 2012, 2012, 510876. [CrossRef]

28. Kendall, G.; Smith, T. Doses to organs and tissues from radon and its decay products. J. Radiol. Prot. 2002, 22, 389. [CrossRef]

29. Islam, G.; Mazumdar, S.; Ashraf, M. Influence of various room parameters upon radon daughter equilibrium indoors. Radiat. Meas. 1996, 26, 193-201. [CrossRef]

30. Grosskopf, A.; Irlweck, K. Radon Exposure and Urinary 210Po Excretion of Austrian Spa Workers. Radiat. Prot. Dosim. 1985, 12, 39-43. [CrossRef]

31. Khursheed, A. Doses to systemic tissues from radon gas. Radiat. Prot. Dosim. 2000, 88, 171-181. [CrossRef]

32. Sakoda, A.; Ishimori, Y.; Fukao, K.; Yamaoka, K.; Kataoka, T.; Mitsunobu, F. Lung dosimetry of inhaled radon progeny in mice. Radiat. Environ. Biophys. 2012, 51, 425-442. [CrossRef]

33. Sakoda, A.; Ishimori, Y.; Yamaoka, K.; Kataoka, T.; Mitsunobu, F. Absorbed doses of lungs from radon retained in airway lumens of mice and rats. Radiat. Environ. Biophys. 2013, 52, 389-395. [CrossRef]

34. Sakoda, A.; Ishimori, Y.; Kawabe, A.; Kataoka, T.; Hanamoto, K.; Yamaoka, K. Physiologically Based Pharmacokinetic Modeling of Inhaled Radon to Calculate Absorbed Doses in Mice, Rats, and Humans. J. Nucl. Sci. Technol. 2010, 47, 731-738. [CrossRef]

35. Stuart, B.O. Deposition and clearance of inhaled particles. Environ. Health Perspect. 1984, 55, 369-390. [CrossRef] 
36. Carvalho, T.C.; Peters, J.I.; Williams, R.O., III. Influence of particle size on regional lung deposition-What evidence is there? Int. J. Pharm. 2011, 406, 1-10. [CrossRef]

37. Hofmann, W. Modelling inhaled particle deposition in the human lung-A review. J. Aerosol Sci. 2011, 42, 693-724. [CrossRef]

38. Harley, N.; Robbins, E. 222Rn alpha dose to organs other than lung. Radiat. Prot. Dosim. 1992, 45, 619-622. [CrossRef]

39. Balásházy, I.; Farkas, Á.; Madas, B.G.; Hofmann, W. Non-linear relationship of cell hit and transformation probabilities in a low dose of inhaled radon progenies. J. Radiol. Prot. 2009, 29, 147. [CrossRef]

40. Oberdörster, G.; Oberdörster, E.; Oberdörster, J. Nanotoxicology: An emerging discipline evolving from studies of ultrafine particles. Environ. Health Perspect. 2005, 113, 823-839. [CrossRef]

41. Ferin, J.; Oberdorster, G.; Penney, D. Pulmonary retention of ultrafine and fine particles in rats. Am. J. Respir. Cell Mol. Biol. 1992, 6, 535-542. [CrossRef]

42. Ferin, J.; Oberdörster, G. Translocation of particles from pulmonary alveoli into the interstitium. J. Aerosol Med. 1992, 5, 179-187. [CrossRef]

43. Paquet, F.; Etherington, G.; Bailey, M.; Leggett, R.; Lipsztein, J.; Bolch, W.; Eckerman, K.; Harrison, J. ICRP publication 130: Occupational intakes of radionuclides: Part 1. Ann. ICRP 2015, 44, 5-188. [CrossRef]

44. Hofmann, W.; Winkler-Heil, R.; Lettner, H.; Hubmer, A.; Gaisberger, M. Radon transfer from thermal water to human organs in radon therapy: Exhalation measurements and model simulations. Radiat. Environ. Biophys. 2019, 58, 513-529. [CrossRef]

45. Sakoda, A.; Ishimori, Y.; Tschiersch, J. Evaluation of the intake of radon through skin from thermal water. J. Radiat. Res. 2016, 57, 336-342. [CrossRef]

46. Lettner, H.; Hubmer, A.; Hofmann, W.; Landrichinger, J.; Gaisberger, M.; Winkler-Heil, R. Radon in the Exhaled Air of Patients in Radon Therapy. Radiat. Prot. Dosim. 2017, 177, 78-82. [CrossRef]

47. Kávási, N.; Kovács, T.; Somlai, J.; Jobbágy, V.; Nagy, K.; Deák, E.; Berhés, I.; Bender, T.; Ishikawa, T.; Tokonami, S. Comparison of urinary excretion of radon from the human body before and after radon bath therapy. Radiat. Prot. Dosim. 2011, 146, 27-30. [CrossRef]

48. Tempfer, H.; Hofmann, W.; Schober, A.; Lettner, H.; Dinu, A. Deposition of radon progeny on skin surfaces and resulting radiation doses in radon therapy. Radiat. Environ. Biophys. 2010, 49, 249-259. [CrossRef]

49. Falkenbach, A.; Kleinschmidt, J.; Soto, J.; Just, G. Radon progeny activity on skin and hair after speleotherapeutic radon exposure. J. Environ. Radioact. 2002, 62, 217-223. [CrossRef]

50. Tobias, C.; Jones, H.; Lawrence, J.; Hamilton, J. The uptake and elimination of krypton and other inert gases by the human body. J. Clin. Investig. 1949, 28, 1375. [CrossRef]

51. Harley, J.H.; Jetter, E.S.; Nelson, N. Elimination of radon from the body. Environ. Int. 1994, 20, 573-584. [CrossRef]

52. Susskind, H.; Atkins, H.L.; Cohn, S.H.; Ellis, K.J.; Richards, P. Whole-body retention of radioxenon. J. Nucl. Med. 1977, 18 , 462-471.

53. Conn, J.R.H.L. Equilibrium distribution of radioxenon in tissue: Xenon-hemoglobin association curve. J. Appl. Physiol. 1961, 16, 1065-1070. [CrossRef]

54. Kirk, W.P.I. In Vivo Behavior and Effects of Krypton-85 in Guinea Pigs; The University of Rochester: Rochester, NY, USA, 1975.

55. Ishimori, Y.; Tanaka, H.; Sakoda, A.; Kataoka, T.; Yamaoka, K.; Mitsunobu, F. Measurements of radon activity concentration in mouse tissues and organs. Radiat. Environ. Biophys. 2017, 56, 161-165. [CrossRef]

56. Nussbaum, E.; Hursh, J. Radon solubility in rat tissues. Science 1957, 125, 552-553. [CrossRef]

57. Henshaw, D.L.; Eatough, J.P.; Richardson, R.B. Radon as a causative factor in induction of myeloid leukaemia and other cancers. Lancet 1990, 335, 1008-1012. [CrossRef]

58. Nussbaum, E.; Harsh, J.B. Radon solubility in fatty acids and triglycerides. J. Phys. Chem. 1958, 62, 81-84. [CrossRef]

59. Schubert, M.; Paschke, A.; Lieberman, E.; Burnett, W.C. Air-water partitioning of 222Rn and its dependence on water temperature and salinity. Environ. Sci. Technol. 2012, 46, 3905-3911. [CrossRef]

60. Sanjon, E.P.; Maier, A.; Hinrichs, A.; Kraft, G.; Drossel, B.; Fournier, C. A combined experimental and theoretical study of radon solubility in fat and water. Sci. Rep. 2019, 9, 10768. [CrossRef]

61. Breustedt, B.; Giussani, A.; Noßke, D. Internal dose assessments-Concepts, models and uncertainties. Radiat. Meas. 2018, 115, 49-54. [CrossRef]

62. Peterman, B.; Perkins, C. Dynamics of radioactive chemically inert gases in the human body. Radiat. Prot. Dosim. 1988, $22,5-12$.

63. Leggett, R.; Marsh, J.; Gregoratto, D.; Blanchardon, E. A generic biokinetic model for noble gases with application to radon. J. Radiol. Prot. 2013, 33, 413. [CrossRef] [PubMed]

64. Harley, N.H. Effect of residential radon decay product dose factor variability on reporting of dose. Health Phys. 2018, 114, 398-407. [CrossRef]

65. Mirsch, J.; Hintz, L.; Maier, A.; Fournier, C.; Löbrich, M. An assessment of radiation doses from radon exposures using a mouse model system. Int. J. Radiat. Oncol. Biol. Phys. 2020, 108, 770-778. [CrossRef]

66. United Nations Scientific Committee on the Effects of Atomic Radiation (UNSCEAR). Sources and Effects of Ionizing Radiation: Sources; United Nations Publications: New York, NY, USA, 2010; Volume 1.

67. Radford, E.P. Potential health effects of indoor radon exposure. Environ. Health Perspect. 1985, 62, 281. [CrossRef]

68. Kreuzer, M.; Sobotzki, C.; Schnelzer, M.; Fenske, N. Factors Modifying the Radon-Related Lung Cancer Risk at Low Exposures and Exposure Rates among German Uranium Miners. Radiat. Res. 2018, 189, 165-176. [CrossRef]

69. Lubin, J.H. Models for the analysis of radon-exposed populations. Yale J. Biol. Med. 1988, 61, 195. 
70. Zhang, Z.-L.; Sun, J.; Dong, J.-Y.; Tian, H.-L.; Xue, L.; Qin, L.-Q.; Tong, J. Residential Radon and Lung Cancer Risk: An Updated Meta-analysis of Case-control Studies. Asian Pac. J. Cancer Prev. 2012, 13, 2459-2465. [CrossRef]

71. Krewski, D.; Lubin, J.H.; Zielinski, J.M.; Alavanja, M.; Catalan, V.S.; Field, R.W.; Klotz, J.B.; Letourneau, E.G.; Lynch, C.F.; Lyon, J.I.; et al. Residential radon and risk of lung cancer: A combined analysis of 7 North American case-control studies. Epidemiology 2005, 16, 137-145. [CrossRef]

72. Chen, J. Lifetime lung cancer risks associated with indoor radon exposure based on various radon risk models for canadian population. Radiat. Prot. Dosim. 2016, 173, 252-258. [CrossRef] [PubMed]

73. Darby, S.; Hill, D.; Auvinen, A.; Barros-Dios, J.M.; Baysson, H.; Bochicchio, F.; Deo, H.; Falk, R.; Forastiere, F.; Hakama, M.; et al. Radon in homes and risk of lung cancer: Collaborative analysis of individual data from 13 European case-control studies. BMJ 2005, 330, 223. [CrossRef] [PubMed]

74. Kreuzer, M.; Fenske, N.; Schnelzer, M.; Walsh, L. Lung cancer risk at low radon exposure rates in German uranium miners. Br. J. Cancer 2015, 113, 1367. [CrossRef] [PubMed]

75. Little, J.B. What are the risks of low-level exposure to $\alpha$ radiation from radon? Proc. Natl. Acad. Sci. USA 1997, 94, 5996-5997. [CrossRef] [PubMed]

76. Franke, A.; Franke, T. Long-term benefits of radon spa therapy in rheumatic diseases: Results of the randomised, multi-centre IMuRa trial. Rheumatol. Int. 2013, 33, 2839-2850.

77. Brooks, A.L.; Hoel, D.G.; Preston, R.J. The role of dose rate in radiation cancer risk: Evaluating the effect of dose rate at the molecular, cellular and tissue levels using key events in critical pathways following exposure to low LET radiation. Int. J. Radiat. Biol. 2016, 92, 405-426. [CrossRef]

78. Charles, M. Radon exposure of the skin: I. Biological effects. J. Radiol. Prot. 2007, 27, 231. [CrossRef]

79. Kristbjornsdottir, A.; Rafnsson, V. Incidence of cancer among residents of high temperature geothermal areas in Iceland: A census based study 1981 to 2010. Environ. Health 2012, 11, 73. [CrossRef]

80. Bräuner, E.V.; Loft, S.; Sørensen, M.; Jensen, A.; Andersen, C.E.; Ulbak, K.; Hertel, O.; Pedersen, C.; Tjønneland, A.; Kjær, S.K. Residential radon exposure and skin cancer incidence in a prospective Danish cohort. PLoS ONE 2015, 10, e0135642. [CrossRef]

81. Ruano-Ravina, A.; Aragonés, N.; Kelsey, K.T.; Pérez-Ríos, M.; Piñeiro-Lamas, M.; López-Abente, G.; Barros-Dios, J.M. Residential radon exposure and brain cancer: An ecological study in a radon prone area (Galicia, Spain). Sci. Rep. 2017, 7, 3595. [CrossRef]

82. Momcilovic, B.; Alkhatib, H.; Duerre, J.; Cooley, M.; Long, W.; Harris, T.; Lykken, G. Environmental lead-210 and bismuth210 accrue selectively in the brain proteins in Alzheimer disease and brain lipids in Parkinson disease. Alzheimer Dis. Assoc. Disord. 2001, 15, 106-115. [CrossRef] [PubMed]

83. Momčilović, B.; Lykken, G.I.; Cooley, M. Natural distribution of environmental radon daughters in the different brain areas of an Alzheimer Disease victim. Mol. Neurodegener. 2006, 1, 11. [CrossRef] [PubMed]

84. Evrard, A.-S.; Hémon, D.; Billon, S.; Laurier, D.; Jougla, E.; Tirmarche, M.; Clavel, J. Childhood leukemia incidence and exposure to indoor radon, terrestrial and cosmic gamma radiation. Health Phys. 2006, 90, 569-579. [CrossRef] [PubMed]

85. International Agency for Research on Cancer. IARC Monographs on the Evaluation of Carcinogenic Risks to Humans: Vol. 100D. A Review of Human Carcinogens: Part D. Radiation; International Agency for Research on Cancer: Lyon, France, 2012.

86. Hall, E.J.; Giaccia, A.J. Radiobiology for the Radiologist; Lippincott Williams \& Wilkins: Philadelphia, PA, USA, 2006 ; Volume 6.

87. Deetjen, P.; Falkenbach, A.; Harder, D.; Jöckel, H.; Kaul, A.; von Philippsborn, H. Radon as a Medicine; Verlag Dr. Kovac: Hamburg, Germany, 2014.

88. Becker, K. One century of radon therapy. Int. J. Low Radiat. 2004, 1, 333-357. [CrossRef]

89. Santos, I.; Cantista, P.; Vasconcelos, C. Balneotherapy in rheumatoid arthritis-A systematic review. Int. J. Biometeorol. 2016, 60, 1287-1301. [CrossRef]

90. Zdrojewicz, Z.; Strzelczyk, J. Radon treatment controversy. Dose Response 2006, 4, 106-118. [CrossRef]

91. EURADON. Indikationsliste/Konsensusliste der Badeärzte des Vereins EURADON. Available online: https://www.euradon.de/ fragen/indikationsliste-der-arge (accessed on 15 June 2020).

92. Erickson, B.E. The therapeutic use of radon: A biomedical treatment in Europe; an "alternative" remedy in the United States. Dose Response 2006, 5, 48-62. [CrossRef]

93. Verhagen, A.; Bierma-Zeinstra, S.; Boers, M.; Cardoso, J.; Lambeck, J.; De Bie, R.; De Vet, H.C. Balneotherapy (or spa therapy) for rheumatoid arthritis. An abridged version of Cochrane Systematic Review. Eur. J. Phys. Rehabil. Med. 2015, 51, 833-847.

94. Lind-Albrecht, G. Einfluss der Radonstollentherapie Auf Schmerzen und Verlauf Bei Spondylitis Ankylosans; Johannes GutenbergUniversität: Mainz, Germany, 1994.

95. Pratzel, H.; Legler, B.; Aurand, K.; Baumann, K.; Franke, T. Wirksamkeitsnachweis von Radonbädern im Rahmen einer kurortmedizinischen Behandlung des zervikalen Schmerzsyndroms. Phys. Med. Rehabil. Kurortmed. 1993, 3, 76-82. [CrossRef]

96. Pratzel, H. Schmerzstillen-der Langzeiteffekt durch Radonbader bei nicht entzundlichen rheumatischen Erkrankungen. Radon Und Gesundh. Radon Health 1999, 163-182.

97. Bellomo, R.; Bagshaw, S.M. Evidence-based medicine: Classifying the evidence from clinical trials-The need to consider other dimensions. Crit. Care 2006, 10, 232. [CrossRef]

98. Franke, A.; Reiner, L.; Pratzel, H.; Franke, T.; Resch, K. Long-term efficacy of radon spa therapy in rheumatoid arthritis-A randomized, sham-controlled study and follow-up. Rheumatology 2000, 39, 894-902. [CrossRef] 
99. Franke, A.; Reiner, L.; Resch, K.L. Long-term benefit of radon spa therapy in the rehabilitation of rheumatoid arthritis: A randomised, double-blinded trial. Rheumatol Int. 2007, 27, 703-713. [CrossRef]

100. Ruhle, P.F.; Fietkau, R.; Gaipl, U.S.; Frey, B. Development of a Modular Assay for Detailed Immunophenotyping of Peripheral Human Whole Blood Samples by Multicolor Flow Cytometry. Int. J. Mol. Sci. 2016, 17, 1316. [CrossRef]

101. Kullmann, M.; Rühle, P.F.; Harrer, A.; Donaubauer, A.; Becker, I.; Sieber, R.; Klein, G.; Fournier, C.; Fietkau, R.; Gaipl, U.S. Temporarily increased TGF $\beta$ following radon spa correlates with reduced pain while serum IL-18 is a general predictive marker for pain sensitivity. Radiat. Environ. Biophys. 2019, 58, 129-135. [CrossRef]

102. Cucu, A.; Shreder, K.; Kraft, D.; Rühle, P.F.; Klein, G.; Thiel, G.; Frey, B.; Gaipl, U.S.; Fournier, C. Decrease of Markers related to Bone erosion in serum of Patients with Musculoskeletal Disorders after serial low-Dose radon spa Therapy. Front. Immunol. 2017, 8, 882. [CrossRef]

103. Rühle, P.F.; Klein, G.; Rung, T.; Tiep Phan, H.; Fournier, C.; Fietkau, R.; Gaipl, U.S.; Frey, B. Impact of radon and combinatory radon/carbon dioxide spa on pain and hypertension: Results from the explorative RAD-ON01 study. Mod. Rheumatol. 2018, 29, 165-172. [CrossRef]

104. Rühle, P.F.; Wunderlich, R.; Deloch, L.; Fournier, C.; Maier, A.; Klein, G.; Fietkau, R.; Gaipl, U.S.; Frey, B. Modulation of the peripheral immune system after low-dose radon spa therapy: Detailed longitudinal immune monitoring of patients within the RAD-ON01 study. Autoimmunity 2017, 50, 133-140. [CrossRef]

105. Van Tubergen, A.; Landewé, R.; Van Der Heijde, D.; Hidding, A.; Wolter, N.; Asscher, M.; Falkenbach, A.; Genth, E.; Thè, H.G.; van der Linden, S. Combined spa-Exercise therapy is effective in patients with ankylosing spondylitis: A randomized controlled trial. Arthritis Care Res. 2001, 45, 430-438. [CrossRef]

106. Moder, A.; Hufnagl, C.; Lind-Albrecht, G.; Hitzl, W.; Hartl, A.; Jakab, M.; Ritter, M. Effect of combined Low-Dose Radon-and Hyperthermia Treatment (LDRnHT) of patients with ankylosing spondylitis on serum levels of cytokines and bone metabolism markers: A pilot study. Int. J. Low Radiat. 2010, 7, 423-435. [CrossRef]

107. Shehata, M.; Schwarzmeier, J.D.; Hilgarth, M.; Demirtas, D.; Richter, D.; Hubmann, R.; Boeck, P.; Leiner, G.; Falkenbach, A. Effect of combined spa-exercise therapy on circulating TGF- $\beta 1$ levels in patients with ankylosing spondylitis. Wien. Klin. Wochenschr. 2006, 118, 266-272. [CrossRef]

108. Dischereit, G.; Neumann, N.; Müller-Ladner, U.; Kürten, B.; Lange, U. Einfluss einer seriellen niedrig-dosierten RadonstollenHyperthermie auf Schmerz, Krankheitsaktivität und zentrale Zytokine des Knochenmetabolismus bei ankylosierender Spondylitis-Eine Prospektivstudie. Aktuelle Rheumatol. 2014, 39, 304-309. [CrossRef]

109. Lange, U.; Muller-Ladner, U.; Dischereit, G. Rheumatic Diseases and Molecular Physical Medicine-New Aspects. Phys. Med. Rehab Kuror 2017, 27, 205-210. [CrossRef]

110. Kazandjieva, J.; Grozdev, I.; Darlenski, R.; Tsankov, N. Climatotherapy of psoriasis. Clin. Dermatol. 2008, 26, 477-485. [CrossRef]

111. Naumann, J.; Sadaghiani, C. Therapeutic benefit of balneotherapy and hydrotherapy in the management of fibromyalgia syndrome: A qualitative systematic review and meta-analysis of randomized controlled trials. Arthritis Res. Ther. 2014, 16 , R141. [CrossRef]

112. Yamaoka, K.; Mitsunobu, F.; Hanamoto, K.; Shibuya, K.; Mori, S.; Tanizaki, Y.; Sugita, K. Biochemical comparison between radon effects and thermal effects on humans in radon hot spring therapy. J. Radiat. Res. 2004, 45, 83-88. [CrossRef]

113. Yamaoka, K.; Mitsunobu, F.; Hanamoto, K.; Mori, S.; Tanizaki, Y.; Sugita, K. Study on biologic effects of radon and thermal therapy on osteoarthritis. J. Pain 2004, 5, 20-25. [CrossRef]

114. Winklmayr, M.; Kluge, C.; Winklmayr, W.; Küchenhoff, H.; Steiner, M.; Ritter, M.; Hartl, A. Radon balneotherapy and physical activity for osteoporosis prevention: A randomized, placebo-controlled intervention study. Radiat. Environ. Biophys. 2015, 54, 123-136. [CrossRef]

115. Lange, U.; Neumann, N.; Kürten, B.; Müller-Ladner, U.; Tarner, I. Einfluss einer seriellen niedrig dosierten RadonstollenHyperthermie auf zentrale Zytokine des Knochen-metabolismus bei ankylosierender Spondylitis. Phys. Med. Rehabil. Kurortmed. 2012, 22, 203-206. [CrossRef]

116. Lange, U.; Dischereit, G.; Tarner, I.; Frommer, K.; Neumann, E.; Müller-Ladner, U.; Kürten, B. The impact of serial radon and hyperthermia exposure in a therapeutic adit on pivotal cytokines of bone metabolism in rheumatoid arthritis and osteoarthritis. Clin. Rheumatol. 2016, 35, 2783-2788. [CrossRef]

117. Lange, U.; Dischereit, G.; Müller-Ladner, U.; Tarner, I.H.; Kürten, B. Einfluss einer kombinierten seriellen RadonstollenHyperthermie auf klinische Parameter und ausgewählte Zytokine bei rheumatoider Arthritis und Osteoarthrose. Phys. Med. Rehabil. Kurortmed. 2017, 27, 87-94. [CrossRef]

118. Nagy, K.; Berhes, I.; Kovacs, T.; Kavasi, N.; Somlai, J.; Kovacs, L.; Barna, I.; Bender, T. Study on endocronological effects of radon speleotherapy on respiratory diseases. Int. J. Radiat. Biol. 2009, 85, 281-290. [CrossRef] [PubMed]

119. Schett, G.; Gravallese, E. Bone erosion in rheumatoid arthritis: Mechanisms, diagnosis and treatment. Nat. Rev. Rheumatol. 2012, 8, 656-664. [CrossRef] [PubMed]

120. Guermazi, A.; Niu, J.; Hayashi, D.; Roemer, F.W.; Englund, M.; Neogi, T.; Aliabadi, P.; McLennan, C.E.; Felson, D.T. Prevalence of abnormalities in knees detected by MRI in adults without knee osteoarthritis: Population based observational study (Framingham Osteoarthritis Study). BMJ 2012, 345, e5339. [CrossRef] [PubMed]

121. Neumann, E.; Junker, S.; Schett, G.; Frommer, K.; Müller-Ladner, U. Adipokines in bone disease. Nat. Rev. Rheumatol. 2016, 12, 296. [CrossRef] [PubMed] 
122. Tennant, F. The physiologic effects of pain on the endocrine system. Pain Ther. 2013, 2, 75-86. [CrossRef]

123. Sabatine, M.S.; Morrow, D.A.; de Lemos, J.A.; Omland, T.; Sloan, S.; Jarolim, P.; Solomon, S.D.; Pfeffer, M.A.; Braunwald, E. Evaluation of multiple biomarkers of cardiovascular stress for risk prediction and guiding medical therapy in patients with stable coronary disease. Circulation 2012, 125, 233-240. [CrossRef]

124. Xu, N.-Y.; Zhang, S.-P.; Dong, L.; Nie, J.-H.; Tong, J. Proteomic analysis of lung tissue of rats exposed to cigarette smoke and radon. J. Toxicol. Environ. Health Part A 2009, 72, 752-758. [CrossRef]

125. Kataoka, T.; Nishiyama, Y.; Toyota, T.; Yoshimoto, M.; Sakoda, A.; Ishimori, Y.; Aoyama, Y.; Taguchi, T.; Yamaoka, K. Radon inhalation protects mice from carbon-tetrachloride-induced hepatic and renal damage. Inflammation 2011, 34, 559-567. [CrossRef]

126. Kataoka, T.; Sakoda, A.; Yoshimoto, M.; Nakagawa, S.; Toyota, T.; Nishiyama, Y.; Yamato, K.; Ishimori, Y.; Kawabe, A.; Hanamoto, K. Studies on possibility for alleviation of lifestyle diseases by low-dose irradiation or radon inhalation. Radiat. Prot. Dosim. 2011, 146, 360-363. [CrossRef]

127. Kataoka, T.; Nishiyama, Y.; Yamato, K.; Teraoka, J.; Morii, Y.; Sakoda, A.; Ishimori, Y.; Taguchi, T.; Yamaoka, K. Comparative study on the inhibitory effects of antioxidant vitamins and radon on carbon tetrachloride-induced hepatopathy. J. Radiat. Res. 2012, 53, 830-839. [CrossRef] [PubMed]

128. Ma, J.; Yonehara, H.; Ikebuchi, M.; Aoyama, T. Effect of radon exposure on superoxide dismutase (SOD) activity in rats. J. Radiat. Res. 1996, 37, 12-19. [CrossRef] [PubMed]

129. Kataoka, T.; Sakoda, A.; Ishimori, Y.; Toyota, T.; Nishiyama, Y.; Tanaka, H.; Mitsunobu, F.; Yamaoka, K. Study of the response of superoxide dismutase in mouse organs to radon using a new large-scale facility for exposing small animals to radon. J. Radiat. Res. 2011, 52, 775-781. [CrossRef] [PubMed]

130. Kataoka, T.; Etani, R.; Kanzaki, N.; Kobashi, Y.; Yunoki, Y.; Ishida, T.; Sakoda, A.; Ishimori, Y.; Yamaoka, K. Radon inhalation induces manganese-superoxide dismutase in mouse brain via nuclear factor- $\mathrm{kB}$ activation. J. Radiat. Res. 2017, 58, 887-893. [CrossRef]

131. Deloch, L.; Derer, A.; Hueber, A.J.; Herrmann, M.; Schett, G.A.; Wölfelschneider, J.; Hahn, J.; Rühle, P.-F.; Stillkrieg, W.; Fuchs, J. Low-dose radiotherapy ameliorates advanced arthritis in hTNF- $\alpha$ tg mice by particularly positively impacting on bone metabolism. Front. Immunol. 2018, 9, 1834. [CrossRef]

132. Takahashi, M.; Kojima, S. Suppression of atopic dermatitis and tumor metastasis in mice by small amounts of radon. Radiat. Res. 2006, 165, 337-342. [CrossRef]

133. Kataoka, T.; Yamato, K.; Nishiyama, Y.; Morii, Y.; Etani, R.; Takata, Y.; Hanamoto, K.; Kawabe, A.; Sakoda, A.; Ishimori, Y. Comparative study on the inhibitory effects of $\alpha$-tocopherol and radon on carbon tetrachloride-induced renal damage. Ren. Fail. 2012, 34, 1181-1187. [CrossRef]

134. Kataoka, T.; Teraoka, J.; Sakoda, A.; Nishiyama, Y.; Yamato, K.; Monden, M.; Ishimori, Y.; Nomura, T.; Taguchi, T.; Yamaoka, K. Protective effects of radon inhalation on carrageenan-induced inflammatory paw edema in mice. Inflammation 2012, 35, 713-722. [CrossRef]

135. Nishiyama, Y.; Kataoka, T.; Yamato, K.; Taguchi, T.; Yamaoka, K. Suppression of dextran sulfate sodium-induced colitis in mice by radon inhalation. Mediat. Inflamm. 2012, 2012, 239617. [CrossRef]

136. Toyota, T.; Kataoka, T.; Nishiyama, Y.; Taguchi, T.; Yamaoka, K. Inhibitory effects of pretreatment with radon on acute alcoholinduced hepatopathy in mice. Mediat. Inflamm. 2012, 2012, 382801. [CrossRef]

137. Nishiyama, Y.; Kataoka, T.; Teraoka, J.; Sakoda, A.; Tanaka, H.; Ishimori, Y.; Mitsunobu, F.; Taguchi, T.; Yamaoka, K. Suppression of streptozotocin-induced type-1 diabetes in mice by radon inhalation. Physiol. Res. 2013, 62, 57-66. [CrossRef] [PubMed]

138. Yamato, K.; Kataoka, T.; Nishiyama, Y.; Taguchi, T.; Yamaoka, K. Antinociceptive effects of radon inhalation on formalin-induced inflammatory pain in mice. Inflammation 2013, 36, 355-363. [CrossRef] [PubMed]

139. Etani, R.; Kataoka, T.; Kanzaki, N.; Sakoda, A.; Tanaka, H.; Ishimori, Y.; Mitsunobu, F.; Yamaoka, K. Difference in the action mechanism of radon inhalation and radon hot spring water drinking in suppression of hyperuricemia in mice. J. Radiat. Res. 2016, 57, 250-257. [CrossRef] [PubMed]

140. Kataoka, T.; Horie, S.; Etani, R.; Kanzaki, N.; Sasaoka, K.; Kobashi, Y.; Hanamoto, K.; Yamaoka, K. Activation of antioxidative functions by radon inhalation enhances the mitigation effects of pregabalin on chronic constriction injury-induced neuropathic pain in mice. Oxidative Med. Cell. Longev. 2016, 2016, 9853692. [CrossRef] [PubMed]

141. Etani, R.; Kataoka, T.; Kanzaki, N.; Sakoda, A.; Tanaka, H.; Ishimori, Y.; Mitsunobu, F.; Taguchi, T.; Yamaoka, K. Protective effects of hot spring water drinking and radon inhalation on ethanol-induced gastric mucosal injury in mice. J. Radiat. Res. 2017, 58, 614-625. [CrossRef] [PubMed]

142. Pei, W.; Tao, L.; Zhang, L.W.; Zhang, S.; Cao, J.; Jiao, Y.; Tong, J.; Nie, J. Circular RNA profiles in mouse lung tissue induced by radon. Environ. Health Prev. Med. 2017, 22, 36. [CrossRef]

143. Paletta, B.; Truppe, W.; Mlekusch, W.; Pohl, E.; Hofmann, W.; Steinhäusler, F. Time function of corticosteroid levels in the blood plasma of rats under the influence of $222 \mathrm{Rn}$ inhalation. Experientia 1976, 32, 652-653. [CrossRef]

144. Taya, A.; Morgan, A.; Baker, S.T.; Humphreys, J.A.; Bisson, M.; Collier, C.G. Changes in the rat lung after exposure to radon and its progeny: Effects on incorporation of bromodeoxyuridine in epithelial cells and on the incidence of nuclear aberrations in alveolar macrophages. Radiat. Res. 1994, 139, 170-177. [CrossRef]

145. Collier, C.G.; Bisson, M.; Baker, S.T.; Eldred, T.; Fritsch, P.; Morlier, J.P.; Monchaux, G. Early cellular responses in rats exposed to radon and radon progeny. Ann. Occup. Hyg. 1997, 41, 86-91. 
146. Cui, F.; Fan, S.; Hu, M.; Nie, J.; Li, H.; Tong, J. Micronuclei rate and hypoxanthine phosphoribosyl transferase mutation in radon-exposed rats. Prog. Nat. Sci. 2008, 18, 1305-1308. [CrossRef]

147. Yamaoka, K.; Komoto, Y.; Suzuka, I.; Edamatsu, R.; Mori, A. Effects of radon inhalation on biological function-lipid peroxide level, superoxide dismutase activity, and membrane fluidity. Arch. Biochem. Biophys. 1993, 302, 37-41. [CrossRef] [PubMed]

148. Kataoka, T.; Etani, R.; Takata, Y.; Nishiyama, Y.; Kawabe, A.; Kumashiro, M.; Taguchi, T.; Yamaoka, K. Radon inhalation protects against transient global cerebral ischemic injury in gerbils. Inflammation 2014, 37, 1675-1682. [CrossRef] [PubMed]

149. ICRP. ICRP Publication 66: Human Respiratory Tract Model for Radiological Protection; Elsevier Health Sciences: Amsterdam, The Netherlands, 1995; Volume 66.

150. Maier, A.; van Beek, P.; Hellmund, J.; Durante, M.; Schardt, D.; Kraft, G.; Fournier, C. Experimental setup for radon exposure and first diffusion studies using gamma spectroscopy. Nucl. Instrum. Methods Phys. Res. Sect. B Beam Interact. Mater. At. 2015, 362, 187-193. [CrossRef]

151. Becker, I.; Donaubauer, A.-J.; Klein, G.; Fournier, C.; Fietkau, R.; Frey, B.; Gaipl, U. P150 Impact of radon SPA on pain and the immune system of patients with musculoskeletal disorders. J. Ann. Rheum. Dis. 2019, 78, A66. [CrossRef]

152. Landrichinger, J.; Holzl, B.; Untner, J.; Foisner, W.; Edtinger, S.; Knapp, M.; Ritter, M.; Gaisberger, M. Radon Registry Study. Acta Physiol. 2017, 221, 108-110.

153. Shaw, A.T.; Gravallese, E.M. Mediators of inflammation and bone remodeling in rheumatic disease. In Seminars in Cell $\mathcal{E}$ Developmental Biology; Academic Press: Cambridge, MA, USA, 2016; pp. 2-10.

154. Morgan, W.F. Non-targeted and delayed effects of exposure to ionizing radiation: I. Radiation-induced genomic instability and bystander effects in vitro. Radiat. Res. 2012, 178, AV223-AV236. [CrossRef]

155. Morgan, W.F. Non-targeted and delayed effects of exposure to ionizing radiation: II. Radiation-induced genomic instability and bystander effects in vivo, clastogenic factors and transgenerational effects. Radiat. Res. 2003, 159, 581-596. [CrossRef]

156. Zaiss, M.M.; Axmann, R.; Zwerina, J.; Polzer, K.; Gückel, E.; Skapenko, A.; Schulze-Koops, H.; Horwood, N.; Cope, A.; Schett, G. Treg cells suppress osteoclast formation: A new link between the immune system and bone. Arthritis Rheum. Off. J. Am. Coll. Rheumatol. 2007, 56, 4104-4112. [CrossRef]

157. Barcellos-Hoff, M.H.; Dix, T.A. Redox-mediated activation of latent transforming growth factor-beta 1. Mol. Endocrinol. 1996, 10, 1077-1083. [CrossRef]

158. Kotake, S.; Udagawa, N.; Hakoda, M.; Mogi, M.; Yano, K.; Tsuda, E.; Takahashi, K.; Furuya, T.; Ishiyama, S.; Kim, K.J. Activated human $\mathrm{T}$ cells directly induce osteoclastogenesis from human monocytes: Possible role of $\mathrm{T}$ cells in bone destruction in rheumatoid arthritis patients. Arthritis Rheum. Off. J. Am. Coll. Rheumatol. 2001, 44, 1003-1012. [CrossRef]

159. Weitzmann, M.N.; Cenci, S.; Haug, J.; Brown, C.; DiPersio, J.; Pacifici, R. B lymphocytes inhibit human osteoclastogenesis by secretion of TGFbeta. J. Cell Biochem. 2000, 78, 318-324. [CrossRef]

160. Lee, B.; Oh, Y.; Jo, S.; Kim, T.H.; Ji, J.D. A dual role of TGF-beta in human osteoclast differentiation mediated by Smad1 versus Smad3 signaling. Immunol. Lett. 2019, 206, 33-40. [CrossRef] [PubMed]

161. Isales, C.M.; Zaidi, M.; Blair, H.C. ACTH is a novel regulator of bone mass. Skelet. Biol. Med. 2010, 1192, 110-116. [CrossRef] [PubMed]

162. Gillmore, G.K.; Perrier, F.; Crockett, R.G. Radon, Health and Natural Hazards; The Geological Society: London, UK, 2018. 